\title{
A fuzzy model integrating shoreline changes, NDVI and settlement influences for coastal zone human impact classification
}

\author{
Rodrigo Mikosz Goncalves ${ }^{\mathrm{a}}$, Ashty Saleem ${ }^{\mathrm{b}}$, Heithor Alexandre Araujo \\ Queiroz $^{\mathrm{a}}$, Joseph Langat Awange ${ }^{\mathrm{b}, \mathrm{c}}$ \\ ${ }^{a}$ Department of Cartographic Engineering, Federal University of Pernambuco (UFPE), \\ Geodetic Science and Technology of Geoinformation Post Graduation Program, Recife, \\ PE, Brazil. \\ ${ }^{b}$ Discipline of Spatial Sciences, School of Earth and Planetary Sciences, Curtin \\ University, Perth, WA, Australia. \\ ${ }^{c}$ Geodetic Institute, Karlsruhe Institute of Technology, Germany
}

\section{ACKNOWLEDGEMENTS}

R. M. Goncalves acknowledges the financial support of project Universal/CNPq14/2012 number: 482224/2012-6; the Coastal Cartographic Laboratory (LACCOST) at Federal University of Pernambuco (Brazil); the Department of Cartographic Engineering (UFPE); the Department of Spatial Sciences (Curtin University), also the support of Post-Doctoral CNPq scholarship (233170/2013-8) that supports his stay at Curtin University, Australia and the support of CNPq Grant 310412/2015-3/PQ and also 310452/2018-0 level 2. R.M. Goncalves and J.L. Awange are also grateful for the Brazilian Science without Borders Program/CAPES Grant 88881.068057/201401, which supported J.L. Awange's stay at the UFPE, Brazil. In addition, J.L. Awange would like to thank the financial support of the Alexander von Humboldt Foundation that supported his time at Karlsruhe Institute

Email address: rodrigo.mikosz@ufpe.br, ashty.saleem@curtin.edu.au, heithorqueiroz@gmail.com, J.Awange@curtin.edu.au (Rodrigo Mikosz Goncalves) 
of Technology. He is grateful to the good working atmosphere provided by his hosts Prof Hansjörg Kutterer and Prof Bernhard Heck. Last but not least, Queiroz would like to thank his master's scholarship supported by CAPES and Saleem is grateful for the opportunity offered to him by Curtin University to undertake his postdoctoral studies. 
$1 \quad$ A fuzzy model integrating shoreline changes, NDVI and z settlement influences for coastal zone human impact classification

3 Abstract

4 Current approaches for obtaining shoreline change rates suffer from inability to give a 5 specialist interpretation of the numerical results represented by velocities $(\mathrm{m} / \mathrm{yr})$. This study proposes a fuzzy model for coastal zone human impact classification that integrates 7 shoreline changes, NDVI, and settlement influences to enhance numerical-linguistic fuzzy classification through Geographical Information System (GIS)'s graphical visualization prowess. The model output representing scores are numbers ranging from zero to one, which are convertible into fuzzy linguistic classification variables; i.e., low, moderate, and high on the one hand. On the other hand, use of GIS through NDVI (Normalized Difference Vegetation Index) provide enhancement through graphic visualization. Using Itamaraca Island in Brazil as an example, multi-temporal satellite images are extracted to provide all the required input variables. The resulting output divides the entire island into five sectors representing both quantitative and qualitative outcomes (i.e., fuzzy classification composed of both scores and maps), showcasing the capability of the proposed approach to complement shoreline change analysis through physical (map) interpretation in addition to the frequently used numbers. The proposed fuzzy model is validated using random in-situ samples and high resolution image data that has been classified by a coastal geomorphology specialist. The accuracy of the interpretation show $81 \%$ of matches are achievable compared to the results of the fuzzy model. The final results delivered by the proposed fuzzy approach shows the complex behavior of the local dynamics, thereby adding useful and substantial information for environmental issues and Integrated Coastal Zone Management.

Keywords: Shoreline, landscape evolution, fuzzy, human impact classification, NDVI, remote sensing. 


\section{Introduction}

Diagnosing anthropogenic impacts (i.e., those associated with human activities) in coastal zones around the world, e.g., coastal development and planning, overfishing, coastal environmental protection and sustainability endeavour, and tourism activities, is part of the Integrated Coastal Zone Management (ICZM) tasks (e.g., Dale et al., 2019, Post and Lundin, 1996, Kenchington and Crawford, 1993, among others). Such diagnosis is relevant to support policy formulation, resources management and conservation, and to pursue sustainable development (Huang and Jin, 2018, Selkoe et al., 2009, Xiqing et al., 2005, Small and Nicholls, 2003, Mazda et al., 2002, Albert and Jorge, 1998). Indeed, efforts to detect the man-made impacts and differentiate their intensities along coastal zones is useful before any stakeholders and government agencies are involved, i.e., once human impacts component related to social economic pressure are identified, practical actions can follow through sequence of interventions (Halpern et al., 2015, Hsu et al., 2007, Sánches-Arcilla et al., 2016).

Even with this realization, considerable differences still exist between anthropogenic coastal zone impact classification at a particular time and spot on the one hand, and the identification of vulnerability (weaknesses in the system) of erosion (e.g. Andrade et al., 2019, Parthasarathy and Natesan, 2015) or the ecological risk (i.e., the combination of probability and impact) assessment (Yanes et al., 2019) on the other hand. Impacts' classification, risks and vulnerability assessment are all essential ingredients of coastal zone management and as such, require methods that can clearly identify impacts and assess vulnerability within the framework of a given budget.

Methods for detecting human impacts along coastal zones include, e.g., shoreline evaluation of erosion/accretion patterns, which is normally detected through (a) topographic profiles analysis (e.g., Jara et al., 2015, Fanos, 1995, Dally and Dean, 1984) considering cross-shore morphology and the balance between destructive and constructive forces acting on a beach, (b) shoreline change rates, e.g., end point rate (EPR), average of rates (AOR), minimum description length (MDL), ordinary least squares (OLS) (e.g. Genz et al., 2007, Dolan et al., 1991, Cenci et al., 2018, Rosskopf et al., 2018, Jin et al., 2015), 
and (c), Land Use/Land Cover (LULC) monitoring combined with shoreline change rates that take advantage of GIS visualization, which has been considered as a successful alternative approach for human impacts detection (e.g., Ghoneim et al., 2015, Guneroglu, 2015). In some cases, the weakness of methods (a), (b), and (c) occur when the human impacts focus only in one variable, making the interpretation rather difficult and tedious hence requiring integration that can be achieved by the fuzzy models (Zadeh, 1965), which enable the inclusion of more socio-economic components such as settlement, population growth, tourism activities, fisheries habitats, and commercial enterprises data, among others (Feng et al., 2006). The fuzzy models have been recognized as alternative methods that combine multiple variables, thereby modeling problems associated with complex environmental systems and eliminating imprecise and subjective concepts is evidenced, e.g., in the work of Lizarazo (2010) who estimate quantitative land cover. Other applications include evolution detection (Hester et al., 2010), mapping soil pollution risk classes detected by heavy metals concentrations (Lourenco et al., 2010), determining the density of sand (Juang et al., 1996), predicting soil erosion in a large watershed (Mitra et al., 1998), capturing coastal geomorphological changes (Hanson et al., 2010), evaluating coastal scenery (Ergin et al., 2004), elucidating the objectives and priorities of North Lebanon's coastal productive sectors and their coastal zone perceptions and knowledge (Meliadou et al., 2012), detecting mesoscale oceanic structures using satellite images (Piedra-Fernandez et al., 2014), and assessing coastal environmental vulnerability (Navas et al., 2012, Silva et al., 2013).

Although fuzzy models can achieve integration and have widely been used as observed above, the problem with them however, is that on the one hand, coastal human impact classification and vulnerability assessments are often undertaken in such manner that the resulting output (i.e., numerical scores that are further converted into linguistic terminologies) lack the visual physical interpretation capability that could easily aid in identification and isolation of the impacts, especially where time and cost are constraining factors. To underscore the importance of integrating numerical/linguistic and physical (i.e., remotely sensed variables that relate directly to anthropogenic interaction), social and economic processes, Klein et al. (1998) and Nicholls and Branson (1998) highlight 
coastal resilience concept considering the uncertain future that addresses the long term needs and vision (Kenchington and Crawford, 1993). On the other hand, the fuzzy models differ in configuration, input variables, output and validation process.

This study proposes a fuzzy model that integrates three variables; (i) shoreline change (detected in three stages, i.e., erosion, accretion and stability) of the coastal zone, over time, (ii) vegetation cover status evaluated by the Normalized Difference Vegetation Index (NDVI), and (iii), settlement influence related with the local planning impact considering the infrastructure and buildings near the shoreline. The novelty lies in the fact that rather than the traditional numerical fuzzy classification of human coastal zone impacts employing only linguistic variables such as high, moderate or low, the study exploits the potentials of using Remote Sensing (RS) data employed within Geographic Information System (GIS) strengthened by others influencing factors that include socio-economic data to enhance the numerical fuzzy classification by enabling graphical visualization through the resulting spatial maps. This is advantageous in that mapping of geographical features enhances the distinguishing of each sectoral evolution pattern recognition (Mondal et al., 2019, Novellino et al., 2019, Valderrama and Flores, 2019, Yan et al., 2019), which may lead to intensive actions of preservation or even regeneration. To demonstrate the feasibility and potential of our proposed fuzzy model, Itamaraca Island (Pernambuco State, Brazil) is employed as a case study where we focus on classifying the fuzzy model output considering levels of human impact from low to high and providing visual interpretation using the 1989, 1996, 2005, 2011 and 2016 temporal Landsat satellite images.

The remainder of the study is organized as follows. In section 2, basics of the fuzzy logic are briefly introduced; Section 3 looks at the input data and the fuzzy modeling's design; Section 4 presents the case study of Itamaraca Island in Brazil. The results are presented and discussed in section 5 and the study concluded in section 6 .

\section{Fuzzy Logic Method: Basics}

In this section, a brief review of the basic fuzzy sets are presented. This is essential to understand the proposed fuzzy model introduced by this study. More details on fuzzy 
logic can be found, e.g., in Jantzen et al., (2013); Grafarend and Awange, (2012); Galindo et al. (2006); Ross et al., (2002), Zadeh (1965), among others.

Definition $(\boldsymbol{f u z z y}$ set): A fuzzy set $A$ over a universe of discourse $X$ (a finite or infinite interval within which the fuzzy set can take a value) is a set of pair

$$
A=\left\{\mu_{A}(x) / x: x \epsilon X, \mu_{A}(x) \epsilon[0,1] \epsilon \Re\right\},
$$

where $\mu_{A}(x)$ is called the membership degree of the element $x$ to the fuzzy set $A$. This degree ranges between the extremes 0 and 1 of the domain of the real numbers. A fuzzy set $A$ in a referral set $U$ is characterized by a membership function, $\mu_{A}(x)$, which associates each element $u$ in $U$ to a real number in the interval $[0,1]$. It is thus defined as a mapping function

$$
\mu_{A}(x): U \rightarrow[0,1]
$$

Fig. 1 exposes an example of a boolean set compared to a fuzzy set representing the height could be considered as tall for a male. To define the set of tall men as a classical set, a predicate $P(x)$ can be used, for instance $x \geq 1.80 \mathrm{~m}$, where $x$ is the height of a person, in this case, if someone has the height of $1.79 \mathrm{~m}$ according to this threshold, the person is considered not being tall. From the fuzzy set of tall men in Fig. 1, a membership can be defined as a sigmoid function, with a height corresponding to a number in the interval $\left[\begin{array}{ll}0 & 1]\end{array}\right.$. In this example, if someone has a height taller than $1.90 \mathrm{~m}$, the membership degree corresponds to 1 . On the other hand, for a height between 1.60 $\mathrm{m}$ and $1.90 \mathrm{~m}$, the membership degree rise gradually and does not jump abruptly.

A linguistic label is a word, in natural language, that expresses or identifies a fuzzy set that may or may not be formal defined. Thus, the membership function $\mu_{A}(x)$ of a fuzzy set $A$ expresses the degree in which $x$ verifies the category specified by $A$. With this definition, concepts such as tall, young, hot, etc. could be used as linguistic variables for expressing abstract concepts. The type of a membership function need to be set for all linguistics variables, which the most commonly used are shown in Fig. 2, e.g., 


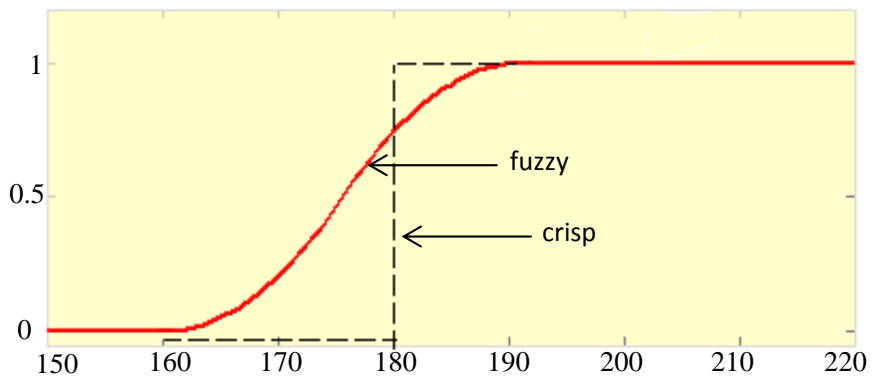

Figure 1: Set of tall men, crisp and fuzzy sets

138 L-function, trapezoidal, triangular and bell.

139 The L-function is defined by two parameters $a$ and $b$, in the following way (Galindo 140 et al., 2006):

$$
L(x)=\left\{\begin{array}{cc}
1 & \text { if } x \leq a \\
\frac{a-x}{b-a} & \text { if } a<x \leq b \\
0 & \text { if } x>b .
\end{array}\right.
$$

141 Trapezoidal function is defined by its lower limit $c$ and its upper limit $f$, and the lower 142 and upper limits of its nucleus, $d$ and $e$, respectively, as

$$
T(x)=\left\{\begin{array}{cc}
0 & \text { if }(x \leq c) \text { or }(x \geq f) \\
(x-c) /(d-c) & \text { if } x \in(c, d] \\
1 & \text { if } x \in(d, e) \\
(f-x) /(f-e) & \text { if } x \in(d, f)
\end{array}\right.
$$

143 while the Gaussian function, a typical Gauss bell, is defined by its mid-value $m$, and the 144 value of $k>0$ as

$$
G(x)=e^{-k(x-m)^{2}}
$$

${ }_{145}$ The greater $k$ is, the narrower the bell becomes. The triangular is defined by its lower 146 limit $g$, its upper limit $i$, and the modal value $m$, so that $g<h<i$, with 


$$
A(x)=\left\{\begin{array}{cc}
0 & \text { if } x \leq g \\
(x-g) /(h-g) & \text { if } x \in(g, h] \\
(i-x) /(i-h) & \text { if } x \in(h, i) \\
1 & \text { if } x \geq i
\end{array}\right.
$$

Fuzzy membership type

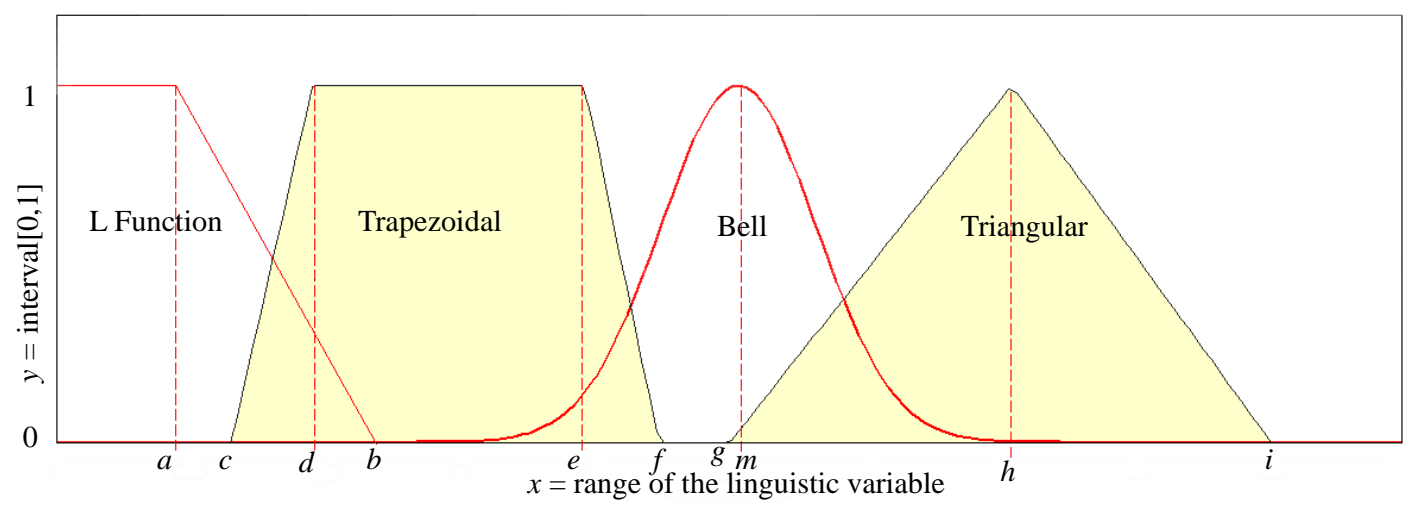

Figure 2: Fuzzy membership types e.g., L-function, trapezoidal, bell, and triangular. 152 of $A$ is less than or equal to that of $B$,

$$
A \subseteq B \equiv \mu_{A}(x) \leq \mu_{B}(x) .
$$

153 The fuzzy union $A \cup B$ is

$$
\mu_{A \cup B}(x) \equiv \max \left(\mu_{A}(x), \mu_{B}(x)\right)
$$


The fuzzy intersection $A \cap B$ is

$$
\mu_{A \cap B}(x) \equiv \min \left(\mu_{A}(x), \mu_{B}(x)\right),
$$

while the fuzzy complement $\bar{A}$ of $\mathrm{A}$ is

$$
\mu_{\bar{A}}(x) \equiv 1-\mu_{A}(x)
$$

Fuzzy rules were built combining the input variables with the output using " $i f$ then" rule format, e.g.,

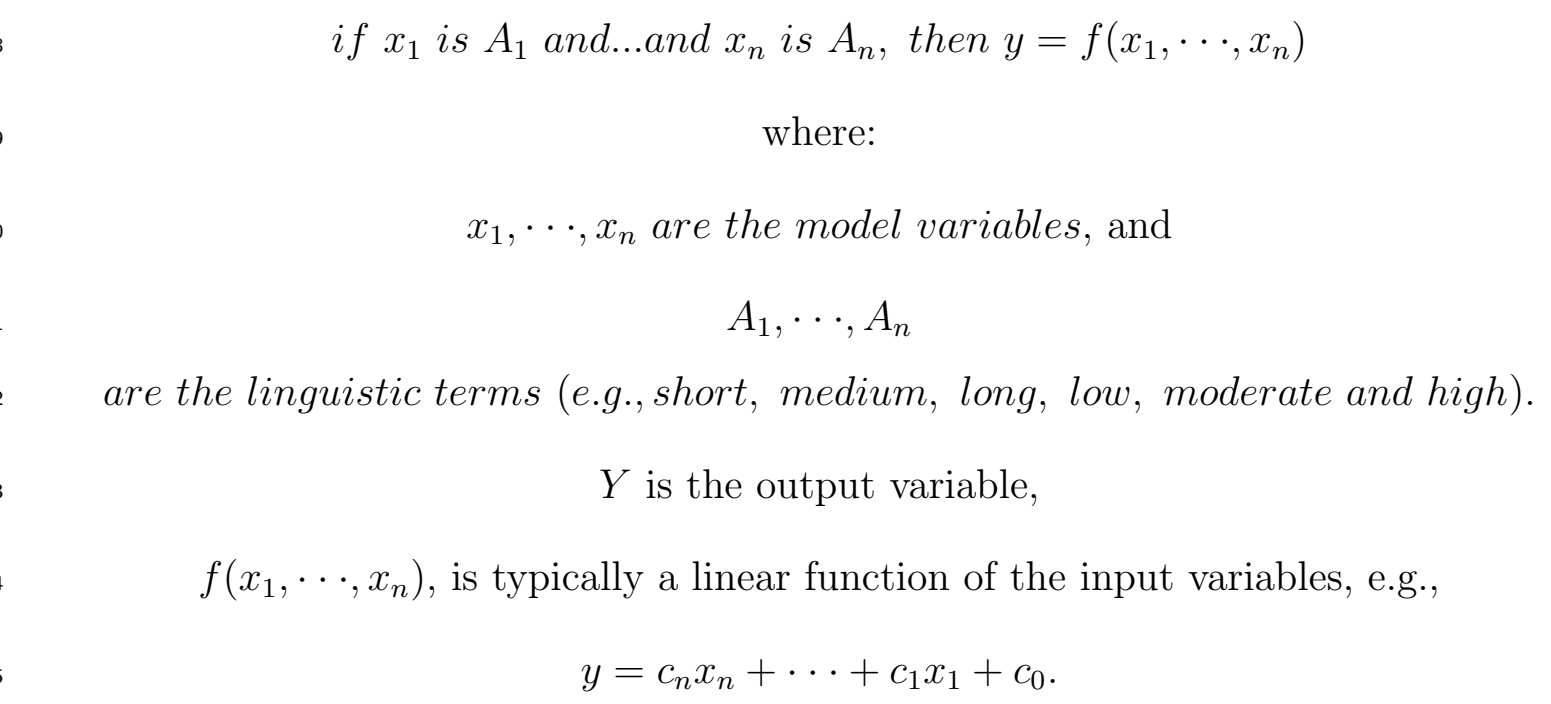

Defuzzification can be considered as the last step of the process that maps a fuzzy set into a crisp value. Some of the methods that can be used in the defuzzification include, e.g., centroid of area, bisector of area, and mean value of maximum, among others. The defuzzification method used in this work was the centroid of area.

\section{Model Design}

The structure of the coastal zone human impact classification is grouped into three steps (step 1, input data; step 2, fuzzy model design; and step 3, validation) as shown in Fig. 3. The first step is data processing to extract shoreline positions from remotely sensed data, shoreline change, NDVI calculations and settlement influence. Thereafter, 
the fuzzy model is designed, in this case, with five variables, i.e., erosion, accretion, stability, NDVI and build up. All linguistics labels (fuzzy sets), membership functions, fuzzy rules, and defuzzification providing the output that is a crisp number representing the coastal zone human impact classification which is designed in step 2. Finally, step 3 validates the model using in-situ comparison assessment. In what follows, a detailed examination of these three steps is presented.

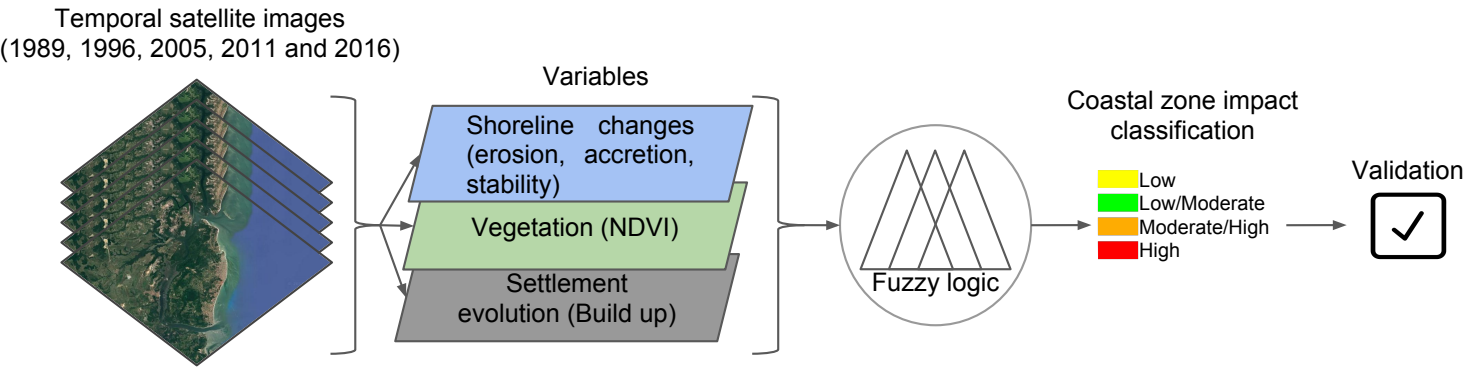

Figure 3: Structure of the fuzzy model for coastal zone human impact classification. Step 1 shows data input from remotely sensed images, step 2 the model design, and step 3 the validation of the model.

\subsection{Step 1: Input data}

The input baseline uses Landsat image (Path/Row, 214/65) to cover the areal extend of the study area. Five Landsat images were selected considering the years 1989, 1996, 2005, 2011, and 2016, and all Landsat images were downloaded from United States Geological Survey (USGS) (https://earthexplorer.usgs.gov/) as Level 1 products (Table 1). The Landsat satellite datasets are selected with consideration to be in the same/nearest months (August and September) for each year, seeking increase the separation of land use classes by minimizing the seasonal variation. Also all selected images should have less than $10 \%$ cloud cover over the study area, but this was not possible for 2005 and 2016 images as most of the time of the year, the study area was covered with clouds, almost everywhere and this represented one of the biggest challenges (data availability) for this study. To be able to overcome cloud cover and select images matching the study criteria, more than one Landsat image was downloaded for 2005 and 2016 (Table 1). The new images for each year (2005 and 2016) were created with zero cloud 
cover using image analysis tool (clip, mask and mosaic techniques over areas covered with cloud) in ArcGIS environment.

Table 1: List of Landsat images used for Shoreline, built up and NDVI calculation

\begin{tabular}{ccccc}
\hline Image No. & Sensor ID & Scene ID & Date & Cloud cover (\%) \\
\hline 1 & TM & LT52140651989255CUB00.tar.gz & $12 / 09 / 1989$ & 28.00 \\
2 & TM & LT52140651996243CUB00.tar.gz & $30 / 08 / 1996$ & 29.00 \\
3a & TM & LT52140652005251CUB00.tar.gz & $08 / 09 / 2005$ & 25.00 \\
3b & TM & LT52140652005267CUB00.tar.gz & $24 / 09 / 2005$ & 42.00 \\
4 & TM & LT52140652011252CUB00.tar.gz & $09 / 09 / 2011$ & 24.00 \\
$5 \mathrm{a}$ & OLI-TIRS & $L C 82140652016266 L G N 00 . t a r . g z$ & $22 / 09 / 2016$ & 25.71 \\
$5 \mathrm{~b}$ & OLI-TIRS & $L C 82140652016250 L G N 00 . t a r . g z$ & $06 / 09 / 2016$ & 27.45 \\
$5 \mathrm{c}$ & OLI-TIRS & $L C 82140652016234 L G N 00 . t a r . g z$ & $21 / 08 / 2016$ & 37.36 \\
\hline
\end{tabular}

Since remotely sensed data are influenced by a number of factors such as atmospheric effects, therefore those datasets cannot be used for further analysis (Tyagi and Bhosle, 2011). Satellite images can only be used after performing number of image pre-processing steps including atmospheric correction to remove or minimize those atmosphere influences to obtain corrected full spectral information for each image element (pixels) (Tyagi and Bhosle, 2014). The dark object subtraction (DOS) is strictly based on image information having this specific characteristic can be considered ideal for this purpose (Chavez, 1996). Since this study will not integrate any ground-based data to be mapped and compared with satellite image information (e.g. land surface temperature), therefore the DOS method can be used to correct and normalize the Landsat image radiance differences which are due to variations considering solar illumination, sensor viewing geometry, and seasonality (Saleem et al., 2018, Gilmore et al., 2015).

The downloaded Landsat images are Level 1 product, therefore the only pre-processing performed after atmospheric correction is the co-registration between Landsat 82016 as the reference image and the rest of Landsat images. This process is performed using image registration workflow in ENVI software. This technique defined many tie points between reference image (Landsat 8 2016) and the rest of Landsat images. All the registered 
Landsat images with reference image have the total RMSE less than 0.5 pixel. A subset image for each Landsat scene is created using the vector dataset for the study area as clipping file in ArcGIS environment.

As input, the fuzzy model uses the satellite images described before to extract information regarding temporal changes, considering three aspects (i) shoreline change; (ii) NDVI; and (iii) settlement evolution.

(i) Shoreline change

Since the study area is surrounded by water in all sides (island), the coastline from each Landsat scene is extracted as polygon shapefile using on-screen manual digitization technique under a similar zooming level (uniform scale of 1:5000). This technique was confirmed by Dewan et al. (2017) to be effective method for coastline and rivers boundaries delineation. Areas of erosion and accretion (sliver polygons) are calculated for every two successive polygons (1989-1996, 1996-2005, 2005-2011, and 2011-2016) using the spatial union tool in ArcGIS environment as suggested, e.g., by Dewan et al. (2017).

Using the five sectors shapefile, the area of erosion, accretion and stability are calculated as percentages in regard to the total area for each sector and those values (\%) has been used as three variables $(X 1, X 2$, and X3) for the first input (shoreline change).

(ii) Normalized Difference Vegetation Index (NDVI)

The second input dataset used in the fuzzy model is NDVI, and this index consists new calculated values for each pixel in the image ranging from -1 to +1 . The NDVI is calculated by the Equation 12 and two required input bands, i.e., near-infrared (NIR) and red (RED) reflectance. The NDVI is calculated for each image (1989, 1996, 2005, 2011, and 2016) after performing image pre-processing including atmospheric correction as the reflectance values are required during this index calculation for more representative vegetation cover. Using the sector shapefile, a mean value of NDVI, for each sector is obtained and has been used as a second input which is representing the fourth variable $\left(X_{4}\right)$. 


$$
N D V I=(N I R-R E D) /(N I R+R E D) .
$$

(iii) Settlement evolution

The third (final) input dataset used is the settlement influence (Built up area). The infrastructure and buildings near shoreline can affect directly coastal erosion as well as flooding. Planning at a local, state or country spheres, a minimum distance for geomorphological aspects preservation near shoreline is very important to reduce the coastal zone human impacts, however, in this study, the opposite can be observed, the increase of settlement advancing near coastline over time.

The object-based algorithm has demonstrated in recent studies its potential in identification land cover mapping in heterogeneous areas with better accuracy than pixel-based image classification (see e.g., Singha et al, 2016, Bisquert et al, 2015, Guan et al, 2013). Also, object-based algorithm analyses treat any image as objects by integrating neighborhood information, which will enhance the analysis and increase the accuracy of the classified image, i.e., LULC. Therefore, for this study, LULC classes (built up, vegetation and others) are extracted from each Landsat image using feature extraction tool in ENVI environment using segmentation approach. During this process, many scale and merge levels are tested to obtain the best result for the three classes including built up areas in all Landsat images. The scale level of 30 and merge level of 95 demonstrated visually the best results, which logically agree with $30 \mathrm{~m}$ spatial resolution of Landsat data. Since an accurate result are required for the fuzzy input, therefore, the segmented raster is converted to vector dataset to delineate the three LULC classes more accurately using manual attribution for the misclassified polygons (areas) for each year in ArcGIS environment during editing session.

The built up area (the third input, Fig 3, settlement influence) classified for each sector and temporal image, and then used as the fifth variable (X5) for the coastal fuzzy classification model. 


\subsection{Step 2: Fuzzy model design}

The fuzzy model design is developed by integrating three inputs: shoreline change; NDVI and settlement influence (built-up area). Those three inputs are consisted of five variables $\left(X 1, X 2, X 3, X_{4}\right.$ and $\left.X 5\right)$. All the input variables detected by the baseline information extracted by satellite images which have a different input range and units according to the specific variables characteristics. In this case X1, X2, X3 (shoreline change) ranges from 0 to 100 (\%) considering the total (\%) of sectoral shoreline variations. The NDVI, variable $X_{4}$, ranges from -1.0 to 1.0 and the $X 5$ (build up) ranges from 0 to $100 \mathrm{~km}^{2}$, which then evaluated by temporal changes. The output of this fuzzy model is a number ranging from 0 to 1 representing a coastal zone human impact classification ranking. When the output number is close to 1 it manifests a high human impact classification and close to 0 refers to low human impact classification, between this range, the fuzzy logic could classified according to the model design as low, low/moderate, moderate, moderate/high or high. The inference method used in proposed fuzzy model is based on Mamdani Model, which adopts a concept of fuzzy rules and outputs represented by fuzzy set resulting from aggregation of each inference rule, see e.g., Jang et al. (1997).

In the fuzzy model, the first input (shoreline change) is divided into three variables (based on the states of the shoreline) erosion (X1), accretion (X2) and stable (X3), considering the changes detected comparing consecutive years e.g. 1989-1996, 1996-2005, 2005-2011 and 2011-2016. The linguistic labels (section 2), considered for this variable is named as low, moderate and high. The type of the membership functions selected is triangular (Equation 6) and L-function (Equation 3) according to the parameters presented in Table 2. 
Table 2: Fuzzy sets. These function numbers represent a mathematical function (triangular or Lfunction) for each specific linguistic labels (low, moderate and high) according to a specific range and variables units $\left(X 1, X_{2}, X_{3}, X_{4}\right.$, and $\left.Y\right)$.

\begin{tabular}{|c|c|c|c|c|}
\hline Variable & Linguistic & Label & Membership & Function \\
\hline \multirow[t]{3}{*}{ Erosion " $X 1$ " } & Low & $(A 1)$ & triangular & {$\left[\begin{array}{lll}-10 & -5 & 10\end{array}\right]$} \\
\hline & Moderate & $(A 2)$ & triangular & {$\left[\begin{array}{lll}4 & 10 & 15\end{array}\right]$} \\
\hline & High & $(A 3)$ & L-function & {$\left[\begin{array}{ll}10 & 12\end{array}\right]$} \\
\hline \multirow[t]{3}{*}{ Accretion " $X 2$ " } & Low & $(B 1)$ & triangular & {$\left[\begin{array}{lll}-10 & -5 & 10\end{array}\right]$} \\
\hline & Moderate & $(B 2)$ & triangular & {$\left[\begin{array}{lll}4 & 10 & 15\end{array}\right]$} \\
\hline & High & $(B 3)$ & L-function & {$\left[\begin{array}{ll}10 & 12\end{array}\right]$} \\
\hline \multirow[t]{3}{*}{ Stable " $X 3 "$} & Low & $(C 1)$ & triangular & {$\left[\begin{array}{lll}-40 & 0 & 40\end{array}\right]$} \\
\hline & Moderate & $(C 2)$ & triangular & {$\left[\begin{array}{lll}30 & 50 & 70\end{array}\right]$} \\
\hline & High & $(C 3)$ & triangular & {$\left[\begin{array}{lll}60 & 100 & 140\end{array}\right]$} \\
\hline \multirow[t]{3}{*}{ NDVI " $X 4$ " } & Low & $(D 1)$ & L-function & {$\left[\begin{array}{lll}-0.2 & 0.3\end{array}\right]$} \\
\hline & Moderate & $(D 2)$ & triangular & {$\left[\begin{array}{llll}0.2 & 0.4 & 0.6\end{array}\right]$} \\
\hline & High & $(D 3)$ & L-function & {$\left[\begin{array}{ll}0.5 & 0.8\end{array}\right]$} \\
\hline \multirow[t]{3}{*}{ Build up " $X 5$ " } & Low & $(E 1)$ & triangular & {$\left[\begin{array}{lll}-10 & -5 & 10\end{array}\right]$} \\
\hline & Moderate & $(E 2)$ & triangular & {$\left[\begin{array}{lll}4 & 10 & 15\end{array}\right]$} \\
\hline & High & $(E 3)$ & triangular & {$\left[\begin{array}{ll}10 & 12\end{array}\right]$} \\
\hline \multirow[t]{3}{*}{ CZHI* Classification " $Y$ " } & Low & $(F 1)$ & L-function & {$\left[\begin{array}{ll}0.2 & 0.4\end{array}\right]$} \\
\hline & Moderate & $(F 2)$ & triangular & {$\left[\begin{array}{lll}0.2 & 0.35 & 0.5\end{array}\right]$} \\
\hline & High & $(F 3)$ & L-function & {$\left[\begin{array}{ll}0.3 & 0.6\end{array}\right]$} \\
\hline
\end{tabular}

*Coastal Zone Human Impact

For the second input $N D V I$ (fourth variable $X_{4}$ ) in the fuzzy model (see Fig 3, step 2), the intervals scale background ranging from -1.0 to 1.0 are based on Lillesand et al. (2014), and represents the vegetation coverage for the surface, i.e., land or water. According to Karaburun (2010), negative values of NDVI represent areas with no vegetation cover, i.e., water bodies and sandy beaches, whereas NDVI $<0.1$ represent infertile soil. On the other hand, moderated values $(0.2<N D V I<0.3)$ represent pasture and shrub, 
while $(0.6<N D V I<0.8)$ refers to tropical and temperate forests, that is, vegetation in healthy conditions (Chouhan and Rao, 2011). The membership functions selected are Lfunction (Equation 3) and triangular (Equation 6), with 3 linguist labels: low, moderate, and high (Table 2).

For the third input (fifth variable X5), the build up, the linguistic labels are named (section 2) as low, moderate and high. The type of the membership functions selected are L-function (Equation 3) and triangular (e.g. Equation 6) according to the parameters presented in Table 2.

Table 2 also presents the fuzzy model output called coastal zone human impact classification $(Y)$. The output uses three linguist labels named as low, moderate and high. The boundaries between the fuzzy sets normally crosses each others, in this case, the coastal zone human impact classification, after the defuzzification process, can be classified into one single linguistic label (low, moderate and high) or also belonging to two classes at the same time, e.g., moderate and high accordingly to the degree of relevance, considering the interval $[0,1]$, thus this is one of the advantages of fuzzy models comparing with Boolean model, it is more flexible.

Finally, using three inputs (shoreline change, NDVI and settlement influence (builtup areas)) with five variables $\left(X 1, X 2, X 3, X_{4}\right.$ and $\left.X 5\right), 17$ fuzzy rules are achieved. The rules, are composed by five variables $\left(X 1, X 2, X_{3}, X_{4}\right.$ and $\left.X 5\right)$ and the linguistics labels for them (A1, A2, A3), (B1, B2, B3), (C1, C2, C3), (D1, D2, D3), (E1, E2, E3) respectively. The final fuzzy rule output $Y(F 1, F 2, F 3)$ are defined by integrating the five variables with their linguistics labels using "if - then" rule format (Section 2) as followed:

Rule 1: If $X 1 \epsilon A 1$ And $X 2 \epsilon B 1$ And $X 3 \epsilon C 3$ And $X 4 \epsilon D 3$ And $X 5 \epsilon E 1$

Then $Y \in F 1$ (another way to express the same rule using, e.g., the linguistics variables is: "If erosion is low and accretion is low and stable is high and NDVI is high, and build $u p$ is low, then the output coastal zone human impact classification is low"); The whole set of rules are presented in the Appendix A: Fuzzy Rules.

It is important to highlight that all these set of variables and rules needs to be val- 
idated, otherwise it might be categorized as arbitrary estimation. In this case, some preliminary testes are done to fine tune the rules and parameters of those functions in an interactive form until satisfied a validation criterion. In this study, a threshold higher than $80 \%$ of matches is adopted and considered in the validation process, section 3.3.

\subsection{Step 3: validation}

The validation step is used to determine the accuracy and quality of the final output (fuzzy coastal zone human impact classification) which is achieved. This accuracy is determined empirically by comparing in-situ samples of ground reference data and high resolution satellite images with the final classification delivered by the fuzzy model. For a complete discussion about the importance of fuzzy assessment, see e.g., Gopal and Woodcock (1994).

\section{Case Study: Itamaraca, Brazil}

The Itamaraca Island (Fig. 4), located at a distance of $48 \mathrm{~km}$ from Recife, is an island on Pernambuco State coast in Brazil, belonging to the Metropolitan Region of Recife, separated from the mainland by Santa Cruz channel. According to the records from the Instituto Brasileiro de Geografia e Estatística (Brazilian Institute of Geography and Statistics) (IBGE, 2010), Itamaraca has a total area of 67 square kilometers and a population of 21,884 people.

The coastal ecosystem of Itamaraca Island is marked by the features of mangrove, rainforest and apicum (or salty), which are characterized as areas of permanent preservation in the Código Florestal Brasileiro (in english, Brazilian Forest Code). Itamaraca falls within the scope of small coastal rivers basins. Its main tributary rivers are Paripe and Jaguaribe. The watercourses are perennial with the native vegetations consisting of evergreen forest and sandbank vegetations. The population pressure on natural resources in this region has implications for economic, social, and environmental terms. These implications justify the need for planning and management actions, which are scarce due to data availability, and the difficulties of acquiring current information. There is also 


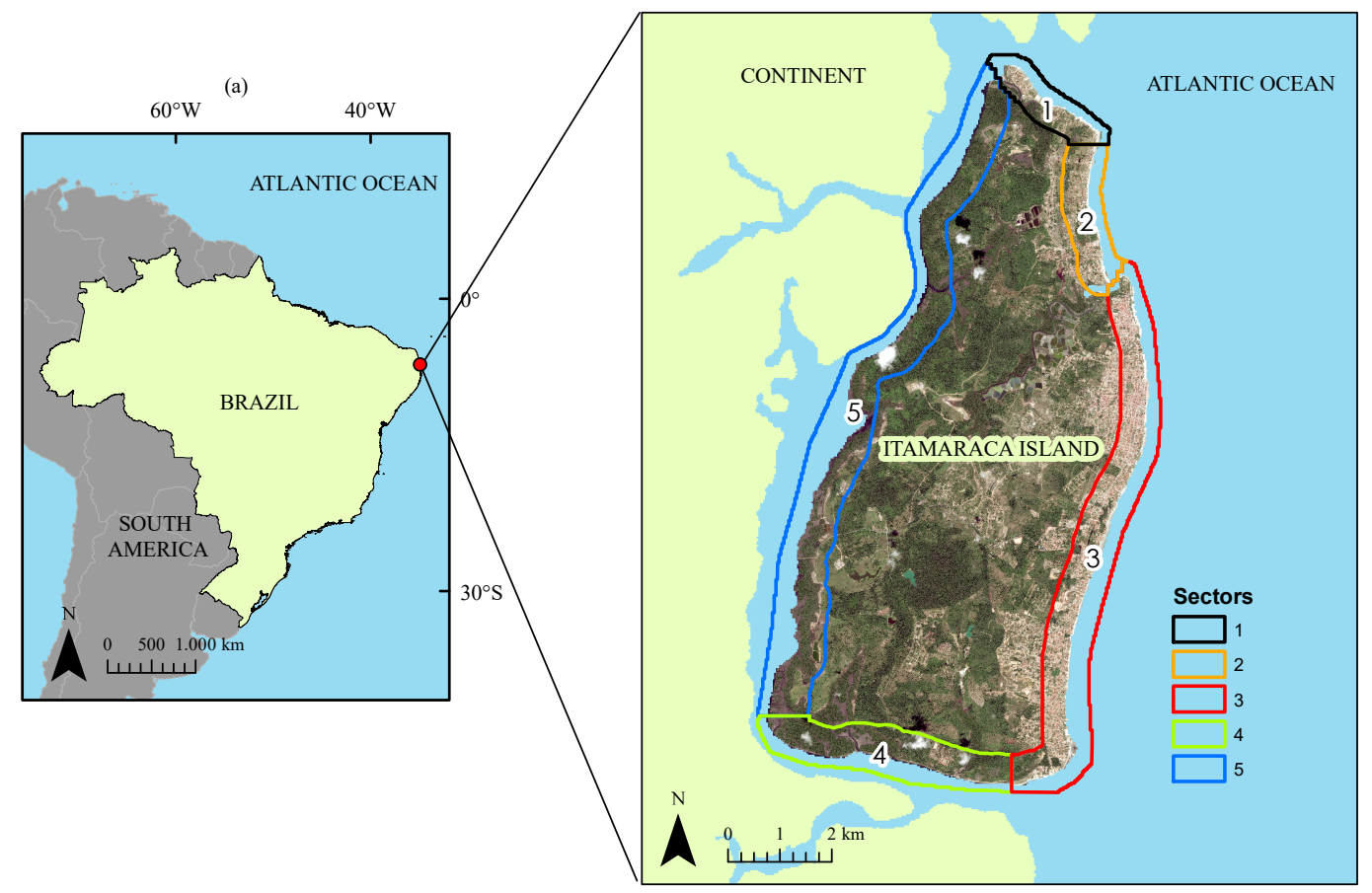

Figure 4: Localization of Itamaraca (a) in Brazil, (b) the island divided in five sectors.

352 another factors that the region is characterized by strong dynamics involving the rivers,

coastal tidal currents, winds and all together have continuous effects on the shoreline status. Fig. 4 (b) also shows the delimitation of the island into five sectors, which are individually examined.

Itamaraca is, however, subjected to remarkable changes of the shoreline, causing significant economic losses to the region, e.g., the destruction of homes and infrastructures as erosion result. The shoreline change is a recurrent phenomenon in the whole Brazilian coast (Souza, 2009) and also around the world. Recent surveys indicate that in addition to the above normal processes in some places, the sea and the sediment transport are constantly changing the coastal zone status and positions (see, e.g., Mendonca et al. (2014), Aiello et al. (2013), Goncalves et al. (2012), Jackson et al. (2012), Smith and Cromley (2012), Baptista et al. (2011), Miller et al. (2011), Banna and Hereheret (2009), Stockdon et al. (2002), Thieler and Danforth (1994)). 


\section{Results and discussion}

\subsection{Shoreline behavior}

Fig. 5 combines the results for shoreline change (a1, a2, a3, a4), land cover classes (b1, $\mathrm{b} 2, \mathrm{~b} 3, \mathrm{~b} 4, \mathrm{~b} 5)$ and final fuzzy classification $(\mathrm{c} 1, \mathrm{c} 2, \mathrm{c} 3, \mathrm{c} 4)$, which represents the outputs for the fuzzy model: coastal zone human impact classification. Fig. 5 (a1, a2, a3, a4) shows the shoreline change, considering 27 years time-line (1989-2016), divided by sectors along Itamaraca Island. In most scenarios, the shoreline has experience changes between advance and retreats with different rates during the evaluated periods, which is consistent with Martins et al. (2017) who reported some stretches of coastline advancing and others retreating, with the highest rates of erosion found near Itamaraca Island (about 0.4 $\mathrm{m} /$ year). Table 3 shows the three classes considering erosion, accretion and stability percentages (\%) among the evaluated study periods (1989-1996, 1996-2005, 2005-2011 and 2011-2016).

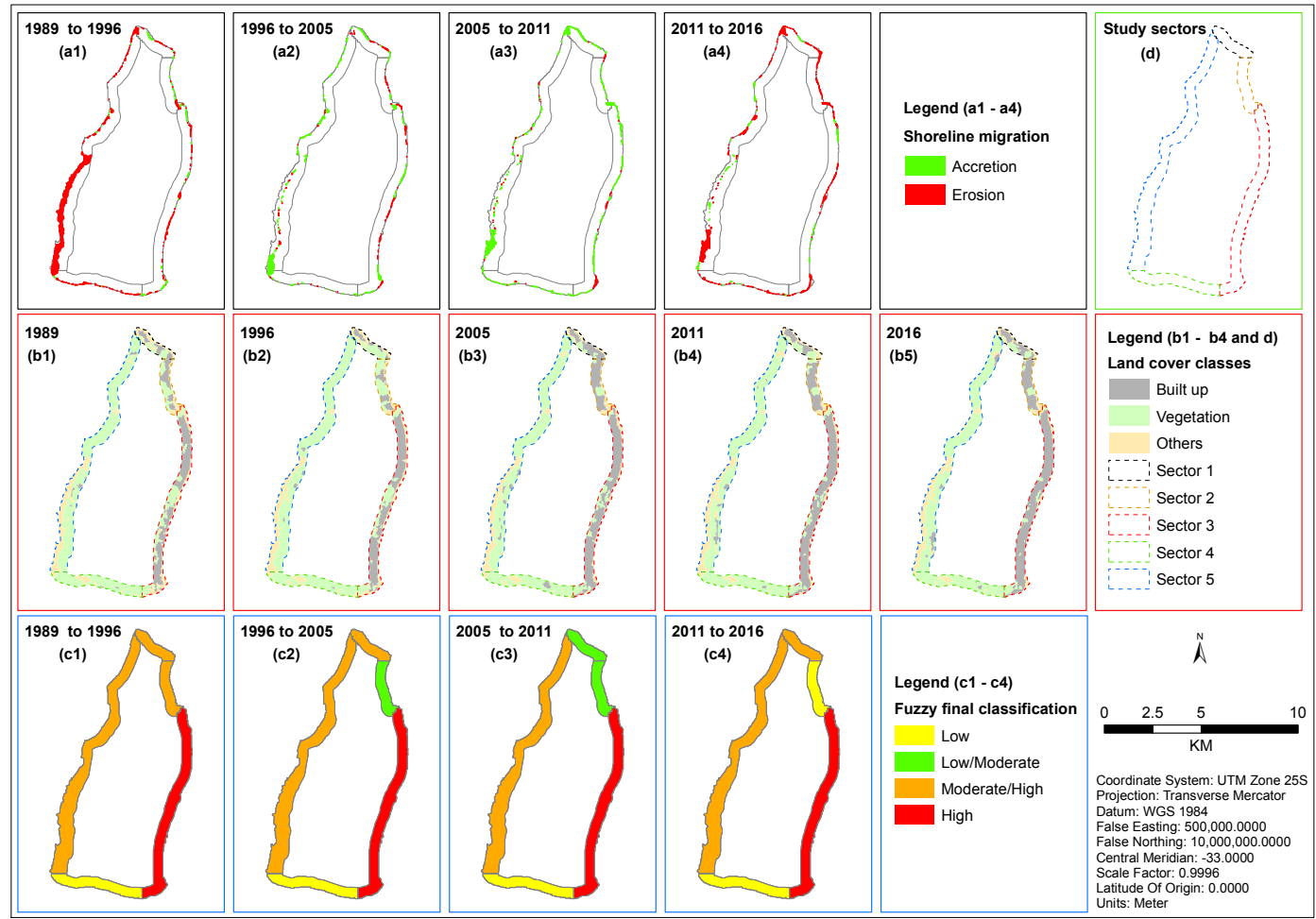

Figure 5: Results of shoreline change, land cover classes, and coastal zone human impact classification using fuzzy model over the sectors during the study periods. 
Table 3: Erosion (E), Accretion (A) and Stability (S) Mean\%

\begin{tabular}{ccccc}
\hline Sectors & $1989-1996$ & $1996-2005$ & $2005-2011$ & $2011-2016$ \\
& $E / A / S$ & $E / A / S$ & $E / A / S$ & $E / A / S$ \\
\hline 1 & $27 / 27 / 46$ & $16 / 14 / 70$ & $15 / 26 / 59$ & $25 / 14 / 61$ \\
2 & $29 / 12 / 60$ & $13 / 23 / 64$ & $11 / 19 / 69$ & $21 / 0 / 79$ \\
3 & $19 / 16 / 64$ & $17 / 17 / 66$ & $20 / 19 / 61$ & $20 / 20 / 60$ \\
4 & $22 / 8 / 71$ & $7 / 30 / 63$ & $16 / 15 / 70$ & $15 / 15 / 70$ \\
5 & $44 / 11 / 45$ & $17 / 28 / 55$ & $14 / 35 / 51$ & $36 / 23 / 41$ \\
\hline
\end{tabular}

On one hand, satellite data utilization makes it possible to detect erosion periods that highlighted sector five between 1989-1996 and 2011-2016 representing 44\% and 36\% of eroded area, respectively. On the other hand, sector two seems to be more stable representing $60 \%, 64 \%, 69 \%$, and $79 \%$ of stability for the four periods (1989-1996), (1996-2005), (2005-2011) and (2011-2016) respectively. For all these four periods, the third sector has experienced more erosion than accretion, Gomes and Silva (2014) affirm that along Pernambuco's coast unprotected areas (like the east side of Itamaraca Island sectors 2 and 3) and because it is in direct contact with Atlantic Ocean that might cause extreme wave events creating strong wave-induced currents, and consequently, the sediments transport would be in constant changes; also there is the sediment transport influence by the Jaguaribe and Paripe rivers around the island. Corroborating to the presented causes, high waves have been reported by Rodriguez et al., (2016), who presented the impacts of Atlantic Ocean on coastal erosion, thus inferring that this could be a direct influence factor on sectors 2 and 3, however, if other parameters are closely observed like the ones proposed in this study (build up and NDVI), it can be seen that erosion is also dependent upon a joined influence parameters.

\subsection{NDVI spatial distribution over the years}

Fig. 6 shows the results for NDVI over the years in each sector. It can be seen that, the sectors 4 and 5 have similar NDVI values and predominantly between 0.57 and 0.67 , while, sectors 1, 2 and 3 show values ranging from 0.33 and 0.47 . 
Regarding these results, the shoreline change can be directly influenced by the presence/absence of vegetation cover, such as presented by Amaral et al., 2016 and Wolfe and Nickling, 1993, who affirm that vegetation is used as a means of stabilizing the mobile sand surfaces, thus reduce shoreline erosion, and consequently influencing the level of human coastal zone impact. And still, the rates of soil loss under natural vegetation cover are usually low and almost have no variations with time, therefore this fact motivates the adoption of vegetation to quantifying the hazards impacts reduction in coastal zones, see e.g., Guannel et al. (2015), Luhar et al. (2010) and Domínguez et al. (2005).

For instance, considering erosion detection (Table 3) and the absence of vegetation cover (Fig. 6 as expressed by NDVI results) for both sectors (1 and 3) and combined with buildings over the beach (Fig. 5 b1 to b5), once can see they are strong indicators for soil and natural vegetation loss. On the other hand, the majority of vegetation coverage in sectors 4 and 5 (Fig. 6) are detected and mapped, and also presents less erosion occurrence and they are mainly predominated by stability coastal status.

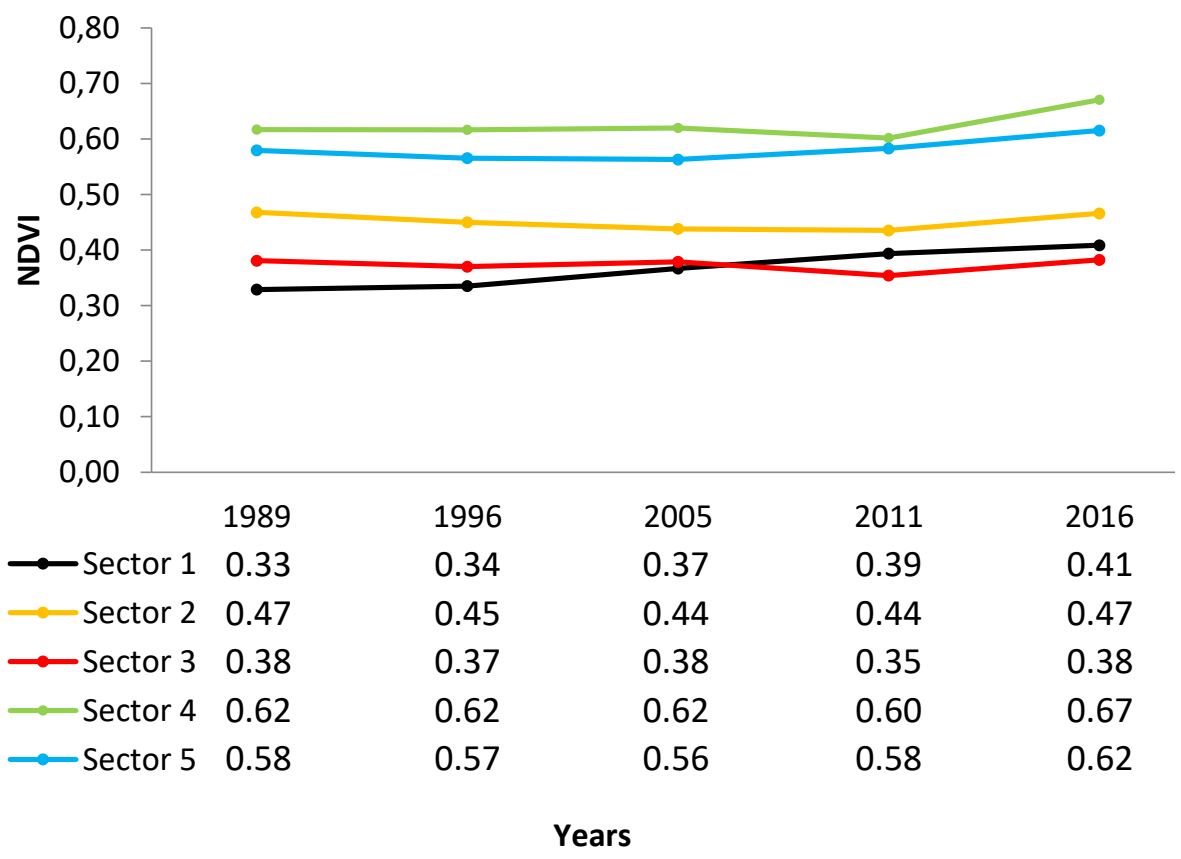

Figure 6: NDVI values for each sector over the years under study. 


\subsection{Build up area evolution near the shoreline}

Silva et al. (2014) pointed out that in many Latin America case studies the increase of inappropriate settlement next to the shoreline, are associated with coastal erosion problems and sediment supply, which is also detected over sectors 1, 2 and 3, which shows buildings very close to the water line (Fig. 5 b1 to b5), thus affecting the natural vegetation growth and therefore increasing the impact on coastal erosion.

Fig. 7 shows the built-up area in square kilometers for all sectors confirming the rising of the building over sector 3 and the stability detection over sector 4 . Fig. 5 b1 to b5 shows the huge difference in buildings areas over sector 3 when it is compared with other sectors, where the man-made areas expanded near the shoreline and this considerably roses over the 27 years of evaluation.

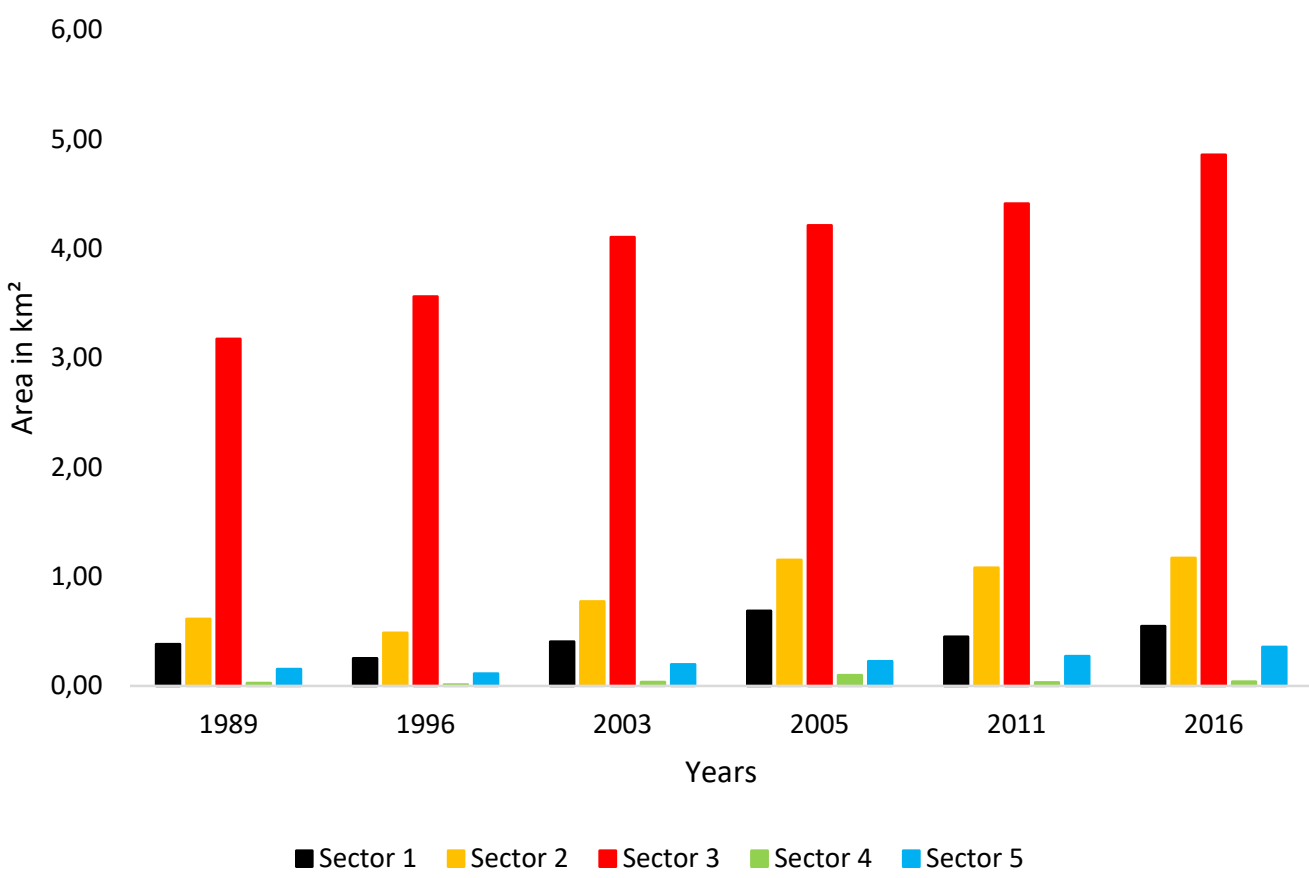

Figure 7: Build up area for each sector over the years under study.

423 Related with buildings in Itamaraca Island, the presence of Orange Fort in south${ }_{424}$ eastern of the island is remarkable. This landmark first built by the Dutch in 1631 and 
rebuilt by the Portuguese in 1654, serving as a military stronghold protective structure as shown in Fig. 8 (b). This place needs constant attention to the coastal managers, once it was abandoned for so long and nowadays restoration intention has been mentioned. It is also highlighted around the build location indicatives of coastal erosion processes with high coastal zone human impact, which can also be worsened by the tourism activities near the shoreline.
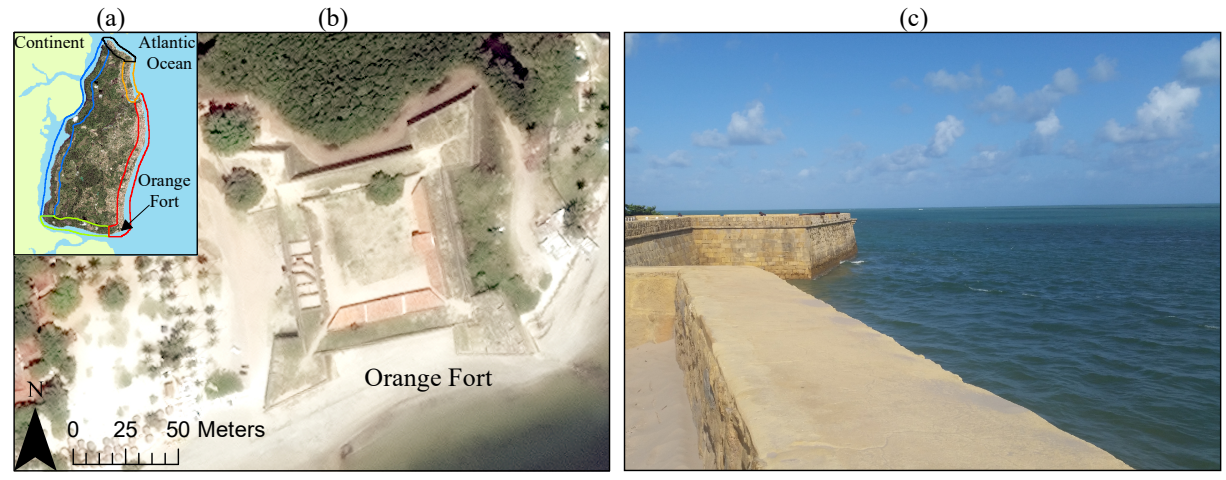

Figure 8: (a) Localization map of Orange Fort in Itamaraca Island, (b) satellite image considering low tide and (c) Orange Fort photograph considering high tide period, presenting the sea almost covering the front wall of it.

\subsection{Coastal zone human impact classification using fuzzy model}

The fuzzy model is implemented to classify coastal zone human impact $(Y)$, and applied along the sectors defined in Fig. 4, based on the input data for five variables named as shoreline change erosion $(X 1)$, accretion (X2), stable (X3), NDVI $\left(X_{4}\right)$ and build up influence (X5). The linguistic classification results are represented in Table 4. Finally, the result is represented by a thematic map shown in Fig. 5 (c1, c2, c3, c4) according to the five sectors in the periods assessed.

The fuzzy classification could belong to two classes at the same time, e.g., sector 2 moderate/low over the periods 1996-2005 and 2005-2011. This flexibility represents the main advantage of the fuzzy classification, highlighting the main trends in the sector evaluated. For the periods 1989-1996, 1996-2005, 2005-2011 and 2011-2016 sectors 3, 4 and 5 are with the same classification over time considered high, low and moderate/high, respectively. 
Sector 5 indicated vegetation presence and less build up and showed moderate/high classification, representing an important sector to keep alert the authorities attention regarding settlement and preserving existing vegetation. The ones in red like sector 3 means that particularly problems related to settlement influence nearshore, combined with low vegetation index and shoreline change (erosion) over years are causing the extreme human impact on coastal zone classification. Sector 1 had maintained the status of moderate/high during all the evaluated periods.

Table 4: Linguistic classification results

\begin{tabular}{ccccc}
\hline Sectors & 1989 to 1996 & 1996 to 2005 & 2005 to 2011 & 2011 to 2016 \\
\hline 1 & moderate/high & moderate/high & moderate/high & moderate/high \\
2 & moderate/high & moderate/low & moderate/low & moderate/high \\
3 & high & high & high & high \\
4 & low & low & low & low \\
5 & moderate/high & moderate/high & moderate/high & moderate/high \\
\hline
\end{tabular}

\subsection{Results Validation}

For validation process, a combination of ground reference data, i.e., samples and scenarios documented by photographs with coordinates (latitude and longitude) and a high resolution image (2016) from Google Earth Pro (Hritz , 2013) are used to validate the outcome of fuzzy final classification map (Fig. $5 \mathrm{c} 4$ ). The field trip data is comparable only for the time when this field data collection took place and this data is not suitable for other temporal data i.e., 2011, 2005, 1996 and 1989. In this case, it is assumed by validating the last period (2011-2016) the outcome of this process could indicate the accuracy of the fuzzy model.

For the 2016 a total of 17 samples are collected and documented for sectors 1, 2 and 3. And to cover unaccessible sectors i.e., 4 and 5, a high resolution image of 2016 from Google Earth Pro (using image slider tool) is used to identified 16 samples to complete the ground reference data (Fig. 9). These particular locations representing 33 samples 
are presented to a coastal geomorphology specialist, who had in mind the variables $X 1$, X2, X3, X4 and X5 to establish the final "matching values" during accuracy assessment process. Table B.5 shows the outcome of this process and $81 \%$ of these locations are matching with the same samples obtained from fuzzy model results.

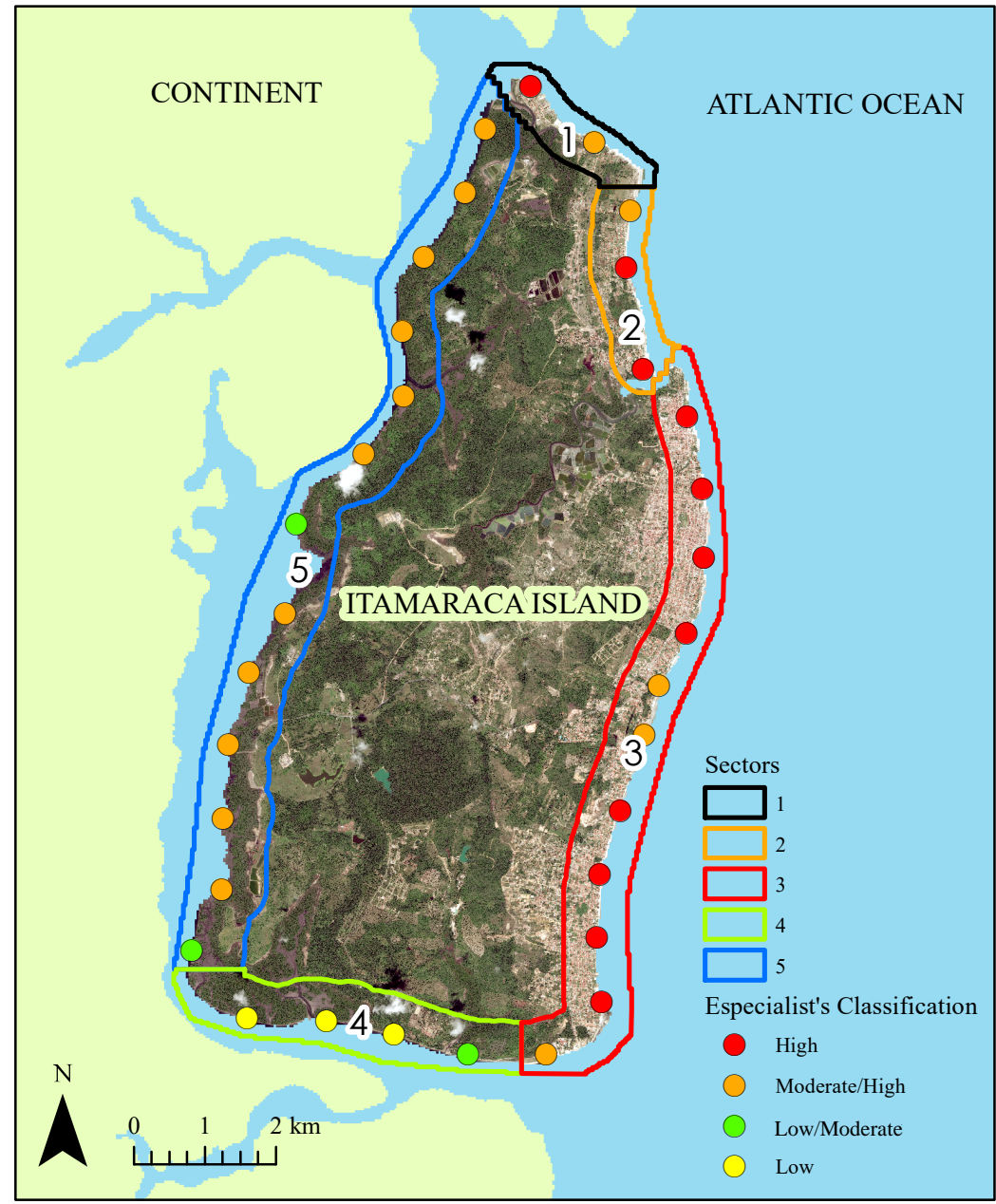

Figure 9: 33 samples (field and high resolution image) for 2016, this referenced data was used to evaluate the results generated from the fuzzy model.

Fig. 10 shows four pictures (a, b, c and d) taken along Itamaraca Island in 2016. Fig. 10 (a) shows an example of destroyed houses by shoreline erosion. The model output 470 ranked this as high coastal zone human impact site, a situation confirmed from the in- 
471 situ data and also by the specialist. Fig. 10 (b) represents a place ranked as high with 472 shoreline erosion shown dying coconut trees due to the salt water bathing its roots (i.e., 473 salinity), Fig. 10 (c) shows a coastal erosion scarp and an erosion evidence, which is 474 ranked by the model as high. Finally, Fig. 10 (d) presents a low site classified from the 475 model showing a mangrove protection scenario. This in situ data is fundamental for the 476 coastal analysis and also useful to validate the fuzzy model effectiveness.

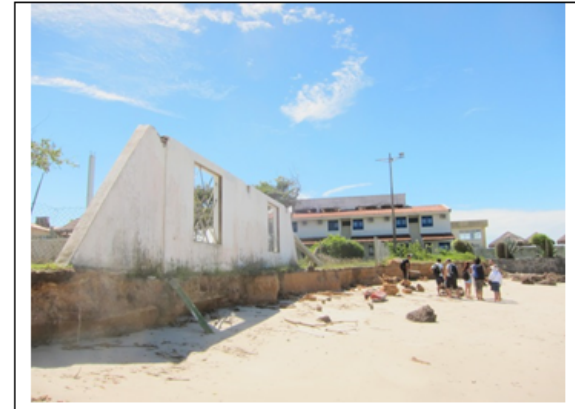

(a) 7०48'31.32"S; 3450'14.56"W

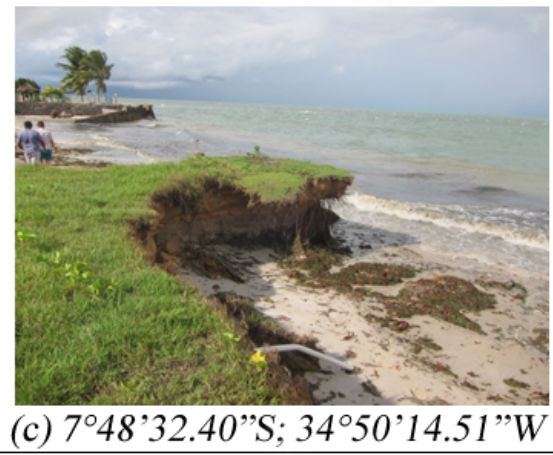

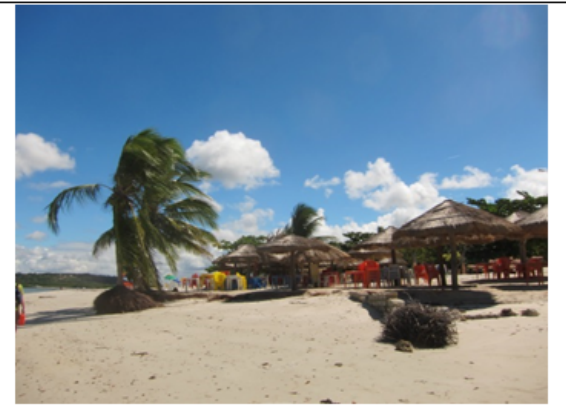

(b) $7^{\circ} 48^{\prime} 23.33 " \mathrm{~S} ; 34^{\circ} 50^{\prime} 12.09^{\prime \prime} \mathrm{W}$

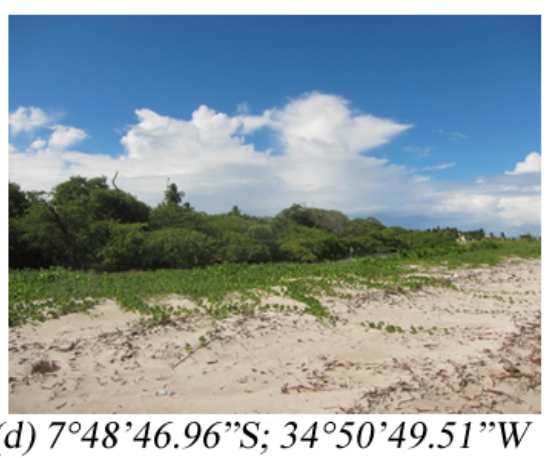

Figure 10: In-situ Assessment (a) destroyed houses, (b) coconut and vegetation affected by salinity (c) coastal erosion scarp, (d) mangrove.

\subsection{Fuzzy model applicability}

This study showed the feasibility of the fuzzy coastal zone impact classification using Itamaraca, Brazil as a case study. The inputs which have been used for the study are available globally for any region and could be obtained by Landsat data as main sources for those inputs. The methodologies which have been applied during this study could be implemented to obtain the required inputs for the fuzzy coastal zone impact assessment, for instance, NDVI, LULC (built-up area) and shoreline change. The rules are simple 
and make possible to define the human impact levels on Itamaraca Island (Fig. 5). The fuzzy modeling is flexible in terms of inputs configuration, therefore, adapting it for other coastal zone study cases regionally or globally is might possible and feasible. For instance, it is desirable to including new input variables like floods information, population, sea level rise impact, among other variables that may be available and might enhance the final outcomes of the fuzzy model significantly.

\section{Conclusion}

The proposed fuzzy model provided a first attempt for coastal zone human impact classification through the integration of both scores and physical remotely sensed data using Itamaraca Island with five sectors as case study for 27 years of the Landsat data evaluation. The remarks of this work are:

1. The proposed fuzzy model provides an alternative way to integrate data (e.g., shoreline change, NDVI, and settlement influence) with ranking (i.e., low, moderate, high) for environmental analysis in multidisciplinary teams for detecting regional or global problems.

2. It is possible for the fuzzy model to give a phenomenon (physical) interpretation to the coastal zone human impact classification, thus simplifying the specialists role of interpreting the results accurately, thereby adding robustness to the fuzzy model's results.

3. The implementation of the proposed fuzzy model by integrating shoreline change, NDVI, and settlement (i.e., geomorphological aspects, in-situ and satellite images) datasets shows improvement in evaluating coastal zone human impacts.

4. From this validation, $81 \%$ of comparison matched, which corroborates the methodology and its feasibility in the present study.

5. Sector 3 was classified as high coastal zone human impact for Itamaraca island, where the importance of integrated coastal zone management considering the actual scenario found in this area highlighted that the area required environmental conservation and preservation actions. 
512 ACKNOWLEDGEMENTS 


\section{Appendix A. Fuzzy Rules}

$$
\text { Rule 1: If } X 1 \epsilon A 1 \text { And } X 2 \epsilon B 1 \text { And } X 3 \epsilon C 3 \text { And } X 4 \epsilon D 3 \text { And } X 5 \epsilon E 1 \text { Then } Y \epsilon F 1
$$

Rule 2: If $X 1 \epsilon A 1$ And $X 2 \epsilon B 1$ And $X 3 \epsilon C 2$ And $X 4 \epsilon D 2$ And $X 5 \epsilon E 1$ Then $Y \epsilon F 1$;

Rule 3: If $X 1 \epsilon A 2$ And $X 2 \epsilon B 2$ And $X 3 \epsilon C 2$ And $X 4 \epsilon D 2$ And $X 5 \epsilon E 2$ Then $Y \epsilon F 2$;

Rule 4: If $X 1 \epsilon A 2$ And $X 2 \epsilon B 2$ And $X 3 \epsilon C 2$ And $X 4 \epsilon D 3$ And $X 5 \epsilon$ E3 Then $Y \epsilon F 3$

Rule 5: If $X 1 \epsilon A 3$ And $X 2 \epsilon B 2$ And $X 3 \epsilon C 1$ And $X 4 \epsilon D 1$ And $X 5 \epsilon E 3$ Then $Y \epsilon F 3$;

Rule 6: If $X 1 \epsilon A 3$ And $X 2 \epsilon B 2$ And $X 3 \epsilon C 2$ And $X 4 \epsilon D 2$ And $X 5 \epsilon E 3$ Then $Y \epsilon F 3$;

Rule 7: If $X 1 \epsilon A 2$ And $X 2 \epsilon B 3$ And $X 3 \epsilon C 2$ And $X 4 \epsilon D 1$ And $X 5 \epsilon E 3$ Then $Y \epsilon F 3$;

Rule 8: If $X 1 \epsilon A 2$ And $X 2 \epsilon B 2$ And $X 3 \epsilon C 3$ And $X 4 \epsilon D 3$ And $X 5 \epsilon E 1$ Then $Y \epsilon F 3$;

Rule 9: If $X 1 \epsilon A 2$ And $X 2 \epsilon B 1$ And $X 3 \epsilon C 3$ And $X 4 \epsilon D 2$ And $X 5 \epsilon E 1$ Then $Y \epsilon F 1$;

Rule 10: If $X 1 \epsilon A 2$ And $X 2 \epsilon B 2$ And $X 3 \epsilon C 3$ And $X 4 \epsilon D 3$ And $X 5 \epsilon E 1$ Then $Y \epsilon F 1$;

Rule 11: If $X 1 \epsilon A 3$ And $X 5 \epsilon E 3$ Then $Y \in F 3$;

Rule 12: If $X 2 \epsilon B 1$ And $X 3 \epsilon C 3$ And $X 4 \epsilon D 3$ Then $Y \epsilon F 1$;

Rule 13: If $X 3 \epsilon C 3$ And $X 4 \epsilon$ D3 Then $Y \epsilon F 1$;

Rule 14: If $X 2 \epsilon B 1$ And $X 3 \epsilon C 3$ Then $Y \in F 1$;

Rule 15: If $X 2 \epsilon B 3$ And $X 3 \epsilon C 2$ And $X 4 \epsilon D 1$ Then $Y \epsilon F 3$;

Rule 16: If $X 1 \epsilon B 2$ And $X 4 \epsilon D 2$ And $X 5 \epsilon E 2$ Then $Y \epsilon F 2$; and

Rule 17: If $X 3 \epsilon C 1$ And $X 4 \epsilon D 2$ Then $Y \in F 2$. 
Table B.5: Validation

\begin{tabular}{|c|c|c|c|}
\hline Samples & $\begin{array}{l}\text { High resolution image and in situ } \\
\text { interpreted by a specialist }\end{array}$ & $\begin{array}{l}\text { Fuzzy model } \\
\text { classification }\end{array}$ & Comparison \\
\hline 1 & High & Moderate/High & Differente \\
\hline 2 & Moderate/High & Moderate/High & Equal \\
\hline 3 & Moderate/High & Low & Differente \\
\hline 4 & Moderate/Low & Low & Differente \\
\hline 5 & Moderate/Low & Low & Differente \\
\hline 6 & High & High & Equal \\
\hline 7 & High & High & Equal \\
\hline 8 & High & High & Equal \\
\hline 9 & High & High & Equal \\
\hline 10 & High & High & Equal \\
\hline 11 & High & High & Equal \\
\hline 12 & High & High & Equal \\
\hline 13 & High & High & Equal \\
\hline 14 & High & High & Equal \\
\hline 15 & High & High & Equal \\
\hline 16 & Moderate/High & High & Differente \\
\hline 17 & Low & Low & Equal \\
\hline 18 & Low & Low & Equal \\
\hline 19 & Low & Low & Equal \\
\hline 20 & Low & Low & Equal \\
\hline 21 & Moderate/Low & Moderate/High & Differente \\
\hline 22 & Moderate/High & Moderate/High & Equal \\
\hline 23 & Moderate/High & Moderate/High & Equal \\
\hline 24 & Moderate/High & Moderate/High & Equal \\
\hline 25 & Moderate/High & Moderate/High & Equal \\
\hline 26 & Moderate/High 30 & Moderate/High & Equal \\
\hline 27 & Moderate/High & Moderate/High & Equal \\
\hline 28 & Moderate/High & Moderate/High & Equal \\
\hline
\end{tabular}




\section{References}

Aiello, A., Canora, F., Pasquariello, G. Spilotro, G. 2013. Shoreline variations and coastal dynamics: A spaceetime data analysis of the Jonian littoral, Italy. Estuarine, Coastal and Shelf Science n.129, p.124-135.

Albert, P., and Jorge, G. 1998. Coastal changes in the Ebro delta: Natural and human factors. Journal of Coastal Conservation, 4(1), 17-26.

Amaral, A. C. Z., Corte, G. N., Denadai, M. R., Colling, L. A., Borzone, C., Veloso, V., ... and Rosa, L. C. D. (2016). Brazilian sandy beaches: characteristics, ecosystem services, impacts, knowledge and priorities. Brazilian Journal of Oceanography, 64(SPE2), 5-16.

Andrade, T. S., Oliveira Sousa, P. H. G., and Siegle, E. 2019. Vulnerability to beach erosion based on a coastal processes approach. Applied Geography, 102, 12-19.

Banna, M.M.E., Hereher M.E. 2009. Detecting temporal shoreline changes and erosion/accretion rates, using remote sensing, and their associated sediment characteristics along the coast of North Sinai, Egypt. Environmental Geology, n.58, 1419-1427.

Baptista, P. Cunha, T., Bernardes, C., Gama C., Ferreira, O., Dias, A. 2011. A Precise and Efficient Methodology to Analyse the Shoreline Displacement Rate. Journal of Coastal Research, 27, 2 p.223-232.

Bisquert, M., Bégué, A., Deshayes, M. 2015. Object-based delineation of homogeneous landscape units at regional scale based on MODIS time series. International Journal of Applied Earth Observation and Geoinformation, 37, 72-82.

Cenci, L., Disperati, L., Persichillo, M. G., Oliveira, E. R., Alves, F. L., and Phillips, M. 2018. Integrating remote sensing and GIS techniques for monitoring and modeling shoreline evolution to support coastal risk management. GIScience and remote sensing, $55(3), 355-375$.

Chavez, P. S., 1996. Image-based atmospheric corrections-revisited and improved. Photogrammetric engineering and remote sensing, 62(9), 1025-1035. 
Chouhan, R; Rao, N. Vegetation Detection in Multispectral Remote Sensing images: Protective Role-Analysis of Vegetation i. 0042 Indian Ocean Tsunami. PDPM Indian Institute of Information Technology, 2011.

Dale, P., Sporne, I., Knight, J., Sheaves, M., Eslami-Andergoli, L., and Dwyer, P. 2019. A conceptual model to improve links between science, policy and practice in coastal management. Marine Policy, 103, 42-49.

Dally, W. R., and Dean, R. G. 1984. Suspended sediment transport and beach profile evolution. Journal of waterway, port, coastal, and ocean engineering, 110(1), 15-33.

Dewan, A., Corner, R., Saleem, A., Rahman, M. M., Haider, M. R., Rahman, M. M., Sarker, M. H., 2017. Assessing channel changes of the Ganges-Padma River system in Bangladesh using Landsat and hydrological data. Geomorphology, 276, 257-279.

Dolan, R., Fenster, M.S., and Holme, S.J., 1991. Temporal analysis of shoreline recession and accretion. Journal of Coastal Research, 7(3), 723-744

Domínguez, L., Anfuso, G., and Gracia, F. J. (2005). Vulnerability assessment of a retreating coast in SW Spain. Environmental Geology, 47(8), 1037-1044.

Ergin, A., Özölçer, İ. H., and Şahin, F. 2010. Evaluating coastal scenery using fuzzy logic: Application at selected sites in Western Black Sea coastal region of Turkey. Ocean Engineering, 37(7), 583-591.

Fanos, A. M. 1995. The impact of human activities on the erosion and accretion of the Nile Delta coast. Journal of Coastal Research, 821-833.

Feng Qi, A-Xing Zhu, Harrower M., Burt J.E., 2006. Fuzzy soil mapping based on prototype category theory. Geoderma 136, 774-787.

Galindo, J., Urrutia, A., Piattini, M., 2006. Fuzzy Databases: Modeling, Design and Implementation. Hershey, PA: IGI Global, 321p. 
Genz, A.S., Flethcer, C.H., Dunn, R.A., Frazer, L.N., Rooney, J.J., 2007. The predictive accuracy of shoreline change rate methods and alongshore beach variation on Maui, Hawaii. Journal of Coastal Research, 23 (1), 87-105.

Gilmore, S., Saleem, A., Dewan, A., 2015. Effectiveness of DOS (Dark-Object Subtraction) method and water index techniques to map wetlands in a rapidly urbanising megacity with Landsat 8 data. Research@ Locate'15, 100-108.

Ghoneim, E., Mashaly, J., Gamble, D., Halls, J., and AbuBakr, M. 2015. Nile Delta exhibited a spatial reversal in the rates of shoreline retreat on the Rosetta promontory comparing pre-and post-beach protection. Geomorphology, 228, 1-14.

Gomes, G., and da Silva, A. C, 2014. Coastal Erosion Case at Candeias Beach (NEBrazil). Journal of Coastal Research, 71(sp1), 30-40.

Goncalves, R.M., Awange, J., Krueger, C.P., Heck, B., Coelho, L.S., 2012. A comparison between three short-term shoreline prediction models. Ocean \& Coastal Management, v. 69, p. $102-110$.

Gopal, S. and Woodcock C., 1994. Theory and methods for accuracy assessment of thematic maps using fuzzy sets. Photogrammetric Engineering and Remote Sensing 60: $81-188$.

Grafarend, E., and J. Awange. 2012. Applications of Linear and Nonlinear Models : Fixed Effects, Random Effects, and Total Least Squares. Berlin: Springer. Springer-Verlag, Berlin, Heidelberge, New York, 1016p.

Guan, H., Li, J., Chapman, M., Deng, F., Ji, Z., Yang, X. 2013. Integration of orthoimagery and lidar data for object-based urban thematic mapping using random forests. International Journal of Remote Sensing, 34(14), 5166-5186.

Guannel, G., Ruggiero, P., Faries, J., Arkema, K., Pinsky, M., Gelfenbaum, G., ... and Kim, C. K. (2015). Integrated modeling framework to quantify the coastal protection services supplied by vegetation. Journal of Geophysical Research: Oceans, 120(1), 324345. 
Guneroglu, A. 2015. Coastal changes and land use alteration on Northeastern part of Turkey. Ocean and Coastal Management, 118, 225-233.

Halpern, B. S., Frazier, M., Potapenko, J., Casey, K. S., Koenig, K., Longo, C., ... and Walbridge, S. 2015. Spatial and temporal changes in cumulative human impacts on the world's ocean. Nature communications, 6, 7615.

Hanson, S., Nicholls, R. J., Balson, P., Brown, I., French, J.R., Spencer, T., Sutherland, W. J., 2010. Capturing coastal geomorphological change within regional integrated assessment: an outcome-driven fuzzy logic approach. Journal of Coastal Research: West Palm Beach (Florida), 26(5), p.831-842.

Hester, D.B., Nelson, S.A.C., Cakir, H.I., Khorram, S., Cheshire, H., 2010. Highresolution land cover change detection based on fuzzy uncertainty analysis and change reasoning. Taylor and Francis: International Journal of Remote Sensing. Vol. 31, n.2, p. $455-475$.

Hritz, C. (2013). A malarial-ridden swamp: using Google Earth Pro and Corona to access the southern Balikh valley, Syria. Journal of Archaeological Science, 40, 1975-1987.

Hsu, T. W., Lin, T. Y., and Tseng, I. F. 2007. Human impact on coastal erosion in Taiwan. Journal of Coastal Research, 961-973.

Huang, Y., and Jin, P. 2018. Impact of human interventions on coastal and marine geological hazards: a review. Bulletin of Engineering Geology and the Environment, $1-10$.

IBGE (Brazilian Institute of Geography and Statistics). "Population Map 2010". Availible in: <http://www.ibge.gov.br/home/geociencias/geografia/mapas_doc1. shtm> Acess: 13/07/2011.

Jackson, C. W. Jr., Alexander, C. R., Bush, D. M., 2012. Application of the AMBUR R package for spatio-temporal analysis of shoreline change: Jekyll Island, Georgia, USA. Computers \& Geosciences n.31, p.199-207. 
Jang. J.S.R., Sun. C.T., Mizutani, E. 1997. Neuro - Fuzzy and soft computing: A computational approach to learning and machine intelligence. London: Prentice Hall, 614 p.

Jantzen, J., 2013. Foundations of fuzzy control : a practical approach. Second edition. Chichester, West Sussex, United Kingdom: John Wiley \& Sons Inc, 325p.

Jara, M. S., González, M., and Medina, R. 2015. Shoreline evolution model from a dynamic equilibrium beach profile. Coastal Engineering, 99, 1-14.

Jin, D., Hoagland, P., Au, D. K., and Qiu, J. 2015. Shoreline change, seawalls, and coastal property values. Ocean and Coastal Management, 114, 185-193.

Juang, C.H., Huang, X.H., Holtz, R.D. E. Chen, J.W., 1996. Determining Relative Density of Sands From CPT Using Fuzzy Sets. Journal of Geothecnical Engineering, ASCE, Vol. 122, n.1, p.1-6.

Karaburun, A. Estimation of C factor for soil erosion modeling using NDVI in Buyukcekmece watershed. Ozean journal

Kenchington, R., and Crawford, D. 1993. On the meaning of integration in coastal zone management. Ocean and Coastal Management, 21(1-3), 109-127.

Klein, R. J., Smit, M. J., Goosen, H., and Hulsbergen, C. H. 1998. Resilience and vulnerability: coastal dynamics or Dutch dikes?. Geographical Journal, 259-268.

Lillesand, T., Kiefer, R. W., Chipman, J. 2014. Remote sensing and image interpretation. John Wiley \& Sons. 7th Edition, p. 763.

Lizarazo, I., 2010. Fuzzy image regions for estimation of impervious surface areas. Taylor and Francis: Remote Sensing Letters. Vol. 1, n. 1, p.19-27.

Lourenco, R. W., Landim, P. M. B., Rosa, A. H., Roveda, J. A. F., Martins, A. C. G., Fraceto, L. F., 2010. Mapping soil pollution by spatial analysis and fuzzy classification. Environmental Earth Sciences 60, 495-504. 
Luhar, M., Coutu, S., Infantes, E., Fox, S., and Nepf, H. (2010). Wave-induced velocities inside a model seagrass bed. Journal of Geophysical Research: Oceans, 115(C12).

Martins, K. A., Souza Pereira, P. D., Silva-Casarín, R., Nogueira Neto, A. V, 2017. The Influence of Climate Change on Coastal Erosion Vulnerability in Northeast Brazil. Coastal Engineering Journal, 59(02), 1740007.

Mazda, Y., Magi, M., Nanao, H., Kogo, M., Miyagi, T., Kanazawa, N., and Kobashi, D. 2002. Coastal erosion due to long-term human impact on mangrove forests. Wetlands Ecology and Management, 10(1), 1-9.

Meliadou, A., Santoro, F., Nader, M.R., Dagher ,M.A., Indary, S.A., Salloum, B.A., 2012. Prioritising coastal zone management issues through fuzzy cognitive mapping approach. Journal of Environmental Management 97, p.56-68.

Mendonca, F.J.B., Goncalves, R.M., Awange, J., Silva, L.M., Gregorio, M.N., 2014. Temporal shoreline series analysis using GNSS. Boletim de Ciencias Geodesicas, v.20, p.701-719.

Miller, E.F., Pondella, D.J., Beck, D.S., Herbinson, K.T. 2011. Decadal-scale changes in southern California sciaenids under different levels of harvesting pressure. ICES Journal of Marine Science, 68(10), 2123-2133.

Mitra, B., Scott, D., Dixon, C. E Mckimmey, J., 1998. Application of fuzzy logic to the prediction of soil erosion in a large watershed. Geoderma, Vol. 86, n.4, p.183- 209.

Mondal, I., Thakur, S., Ghosh, P., De, T. K., and Bandyopadhyay, J. 2019. Land Use/Land Cover Modeling of Sagar Island, India Using Remote Sensing and GIS Techniques. In Emerging Technologies in Data Mining and Information Security (pp. 771-785). Springer, Singapore.

Navas, J.M., Telfer, T.C., Ross, L.G., 2012. Separability indexes and accuracy of neurofuzzy classification in Geographic Information Systems for assessment of coastal environmental vulnerability. Ecological Informatics, n.12, p.43-49. 
Nicholls, R. J., and Branson, J. 1998. Coastal resilience and planning for an uncertain future: an introduction. The Geographical Journal, 164(3), 255-258.

Novellino, A., Jordan, C., Ager, G., Bateson, L., Fleming, C., and Confuorto, P. 2019. Remote sensing for natural or man-made disasters and environmental changes. In Geological Disaster Monitoring Based on Sensor Networks (pp. 23-31). Springer, Singapore.

Parthasarathy, A., and Natesan, U. 2015. Coastal vulnerability assessment: a case study on erosion and coastal change along Tuticorin, Gulf of Mannar. Natural Hazards, 75(2), 1713-1729.

Piedra-Fernandez, J.A., Ortega, G.O., Wang, J.Z. Canton-Garbin M., 2014. Fuzzy content-based image retrieval for oceanic remote sensing. IEEE Transactions on Geoscience and Remote Sensing, Vol.52, n.9, p.5422-5431.

Post, J. C., and Lundin, C. G. (Eds.). 1996. Guidelines for integrated coastal zone management. The World Bank.

Rodríguez, M. G., Nicolodi, J. L., Gutiérrez, O. Q., Losada, V. C., Hermosa, A. E, 2016. Brazilian coastal processes: wind, wave climate and sea level. In Brazilian Beach Systems (pp. 37-66). Springer, Cham.

Ross, T.J., Booker, J.M. and Parkinson J.W., 2002. Fuzzy Logic and Probability Applications: Bringing the Gap. ASA-SIAM Series on Statistics and Applied Mathematics, 409p.

Rosskopf, C. M., Di Paola, G., Atkinson, D. E., Rodríguez, G., and Walker, I. J. 2018. Recent shoreline evolution and beach erosion along the central Adriatic coast of Italy: the case of Molise region. Journal of coastal conservation, 22(5), 879-895.

Saleem, A., Corner, R., Awange, J., 2018. On the possibility of using CORONA and Landsat data for evaluating and mapping long-term LULC: Case study of Iraqi Kurdistan. Applied geography, 90, 145-154. 
Sánchez-Arcilla, A., García-León, M., Gracia, V., Devoy, R., Stanica, A., and Gault, J. 2016. Managing coastal environments under climate change: Pathways to adaptation. Science of the total environment, 572, 1336-1352.

Selkoe, K. A., Halpern, B. S., Ebert, C. M., Franklin, E. C., Selig, E. R., Casey, K. S., ... and Toonen, R. J. 2009. A map of human impacts to a "pristine" coral reef ecosystem, the Papahanaumokuakea Marine National Monument. Coral Reefs, 28(3), 635-650.

Silva, R., Martínez, M. L., Hesp, P. A., Catalan, P., Osorio, A. F., Martell, R., Cienguegos, R., 2014. Present and future challenges of coastal erosion in Latin America. Journal of Coastal Research, 71(sp1), 1-16.

Silva, L.M., Goncalves, R.M., Lira, M.M.S., Pereira, P.S., 2013. Fuzzy modeling applied to coastal erosion vulnerability detection. Boletim de Ciencias Geodesicas, n.19, p.746764.

Singha, M., Wu, B., Zhang, M. 2016. An object-based paddy rice classification using multi-spectral data and crop phenology in Assam, Northeast India. Remote Sensing, $8(6), 479$.

Small, C., and Nicholls, R. J. 2003. A global analysis of human settlement in coastal zones. Journal of coastal research, 584-599.

Smith, M. J., Cromley, R. G., 2012. Measuring Historical Coastal Change using GIS and the Change Polygon Approach. Transactions in GIS, 16(1), p.3-15.

Souza, C. R. G., 2009. Coastal erosion and the coastal zone management challenges in Brazil. Journal of Integrated Coastal Zone Management. v.9, n.1, p.17-37.

Stockdon, H. F., Sallenger J.R., Asbury H., Jeffrey, H. List, Holman. R. A., 2002. Estimation of Shoreline Position and Change using Airborne Topographic Lidar Data. Journal of Coastal Research 18, 3, p.502-513.

Thieler, E. R., Danforth W. W., 1994. Historical Shoreline Mapping (I): Improving Techniques and Reducing Positioning Errors. Journal of Coastal Research, 10, 3, p.549-563. 
Tyagi, P., and Bhosle, U, 2011. Atmospheric correction of remotely sensed images in spatial and transform domain. International Journal of Image Processing, 5(5), 564579.

Tyagi, P., and Bhosle, U, 2014. Radiometric correction of Multispectral Images using Radon Transform. Journal of the Indian Society of Remote Sensing, 42(1), 23-34.

Valderrama-Landeros, L., and Flores-de-Santiago, F. 2019. Assessing coastal erosion and accretion trends along two contrasting subtropical rivers based on remote sensing data. Ocean and Coastal Management, 169, 58-67.

Wolfe, S. A., and Nickling, W. G. (1993). The protective role of sparse vegetation in wind erosion. Progress in physical geography, 17(1), 50-68.

Xiqing, C., Erfeng, Z., Hongqiang, M., and Zong, Y. 2005. A preliminary analysis of human impacts on sediment discharges from the Yangtze, China, into the sea. Journal of Coastal Research, 515-521.

Yang, C., Li, Q., Hu, Z., Chen, J., Shi, T., Ding, K., and Wu, G. 2019. Spatiotemporal evolution of urban agglomerations in four major bay areas of US, China and Japan from 1987 to 2017: Evidence from remote sensing images. Science of The Total Environment.

Yanes, A., Botero, C. M., Arrizabalaga, M., and Vásquez, J. G. 2019. Methodological proposal for ecological risk assessment of the coastal zone of Antioquia, Colombia. Ecological Engineering, 130, 242-251.

Zadeh, L.A., 1965. Fuzzy Sets. Information and Control 8, 338-353. 


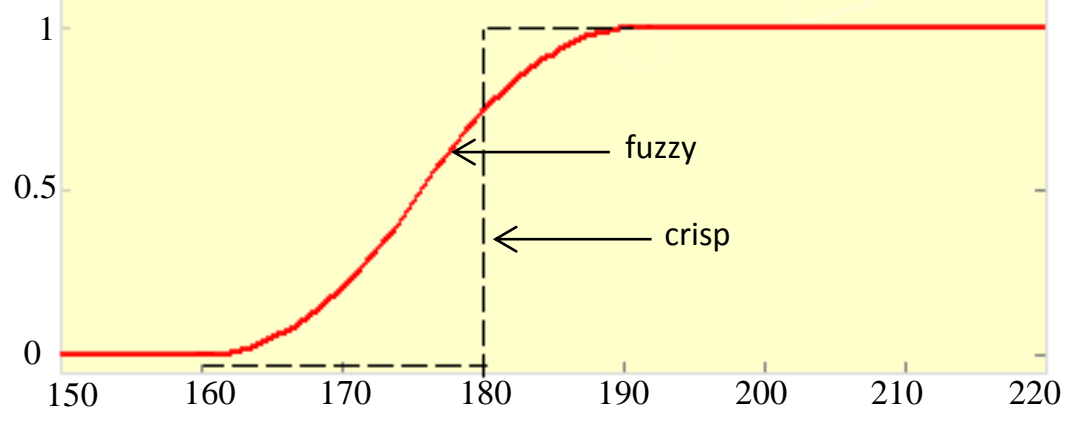




\section{Fuzzy membership type}

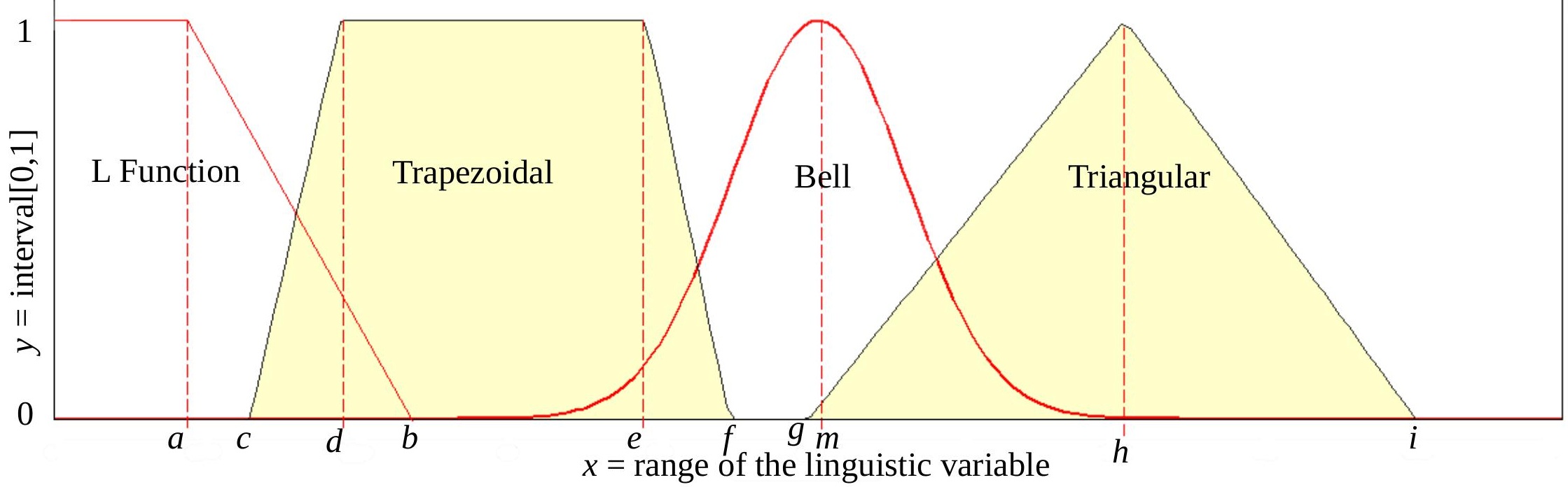


Temporal satellite images

(1989, 1996, 2005, 2011 and 2016)

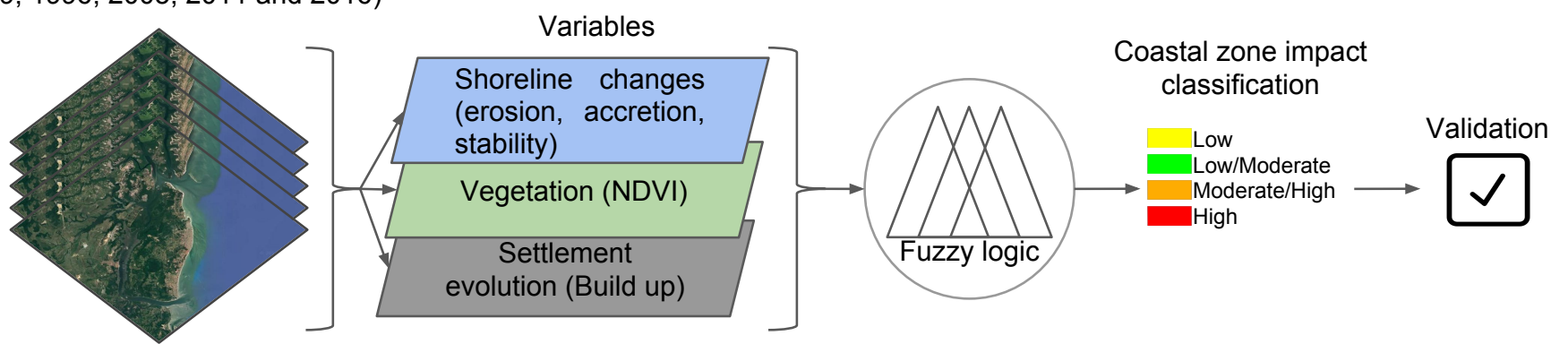




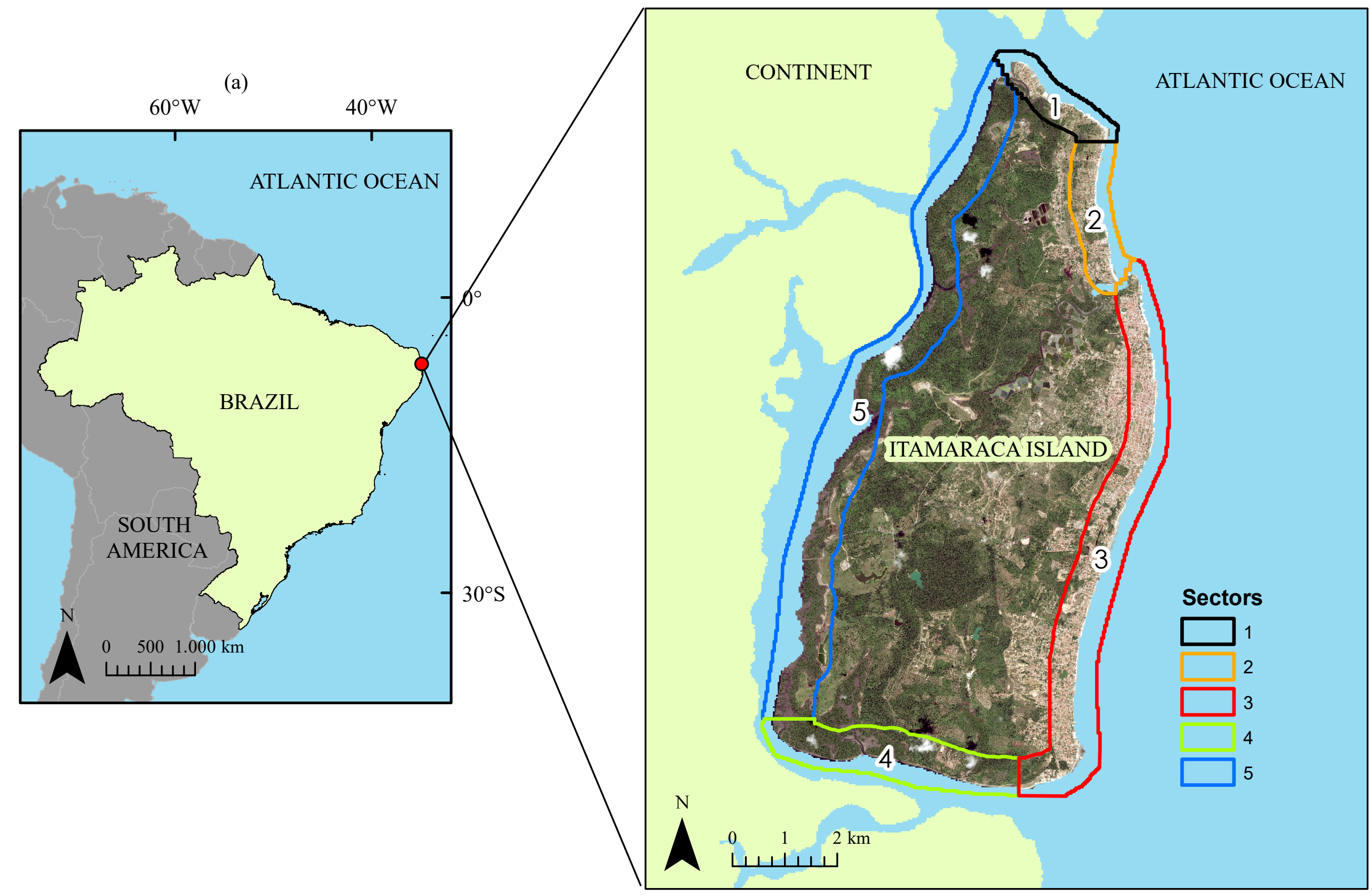




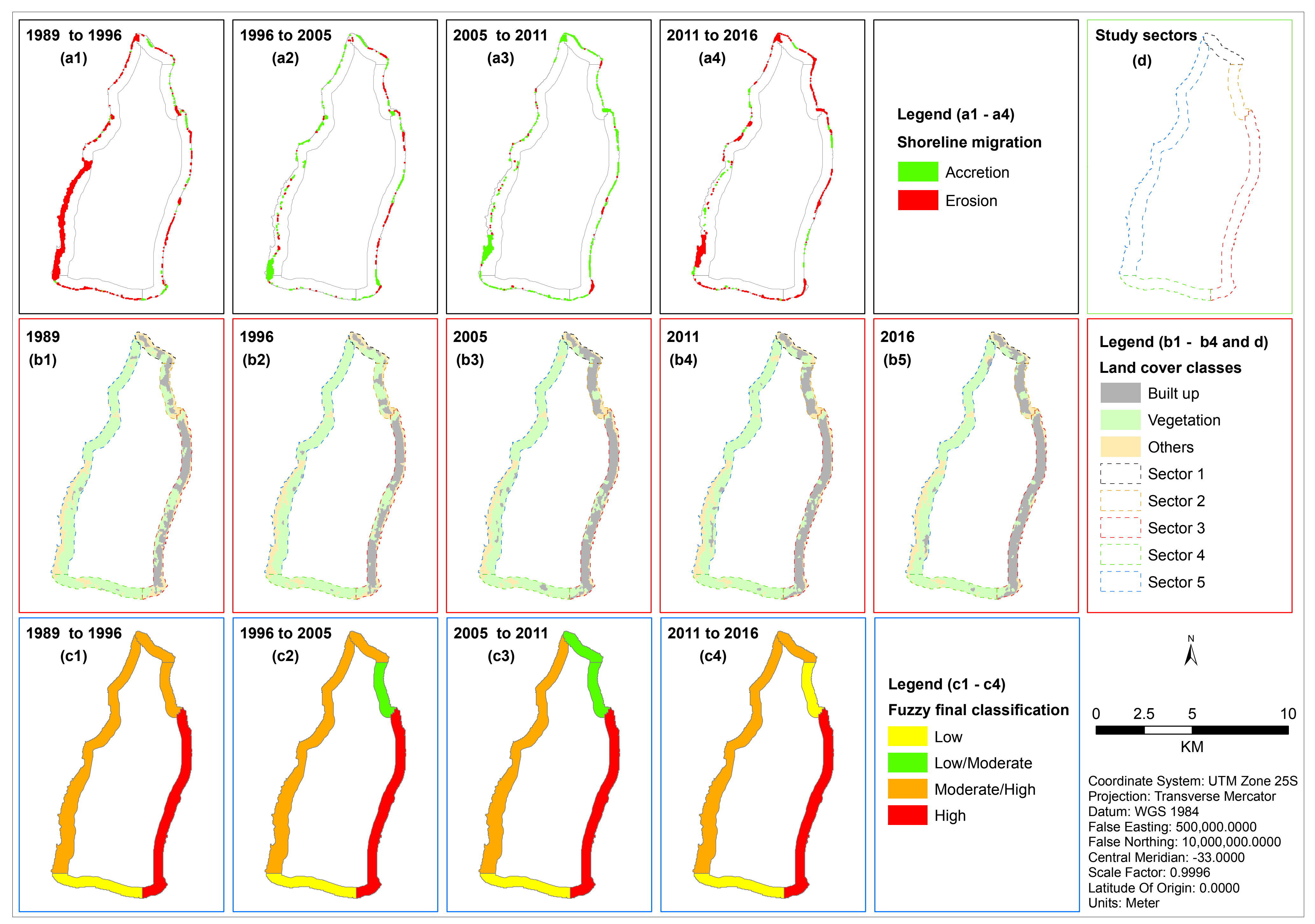




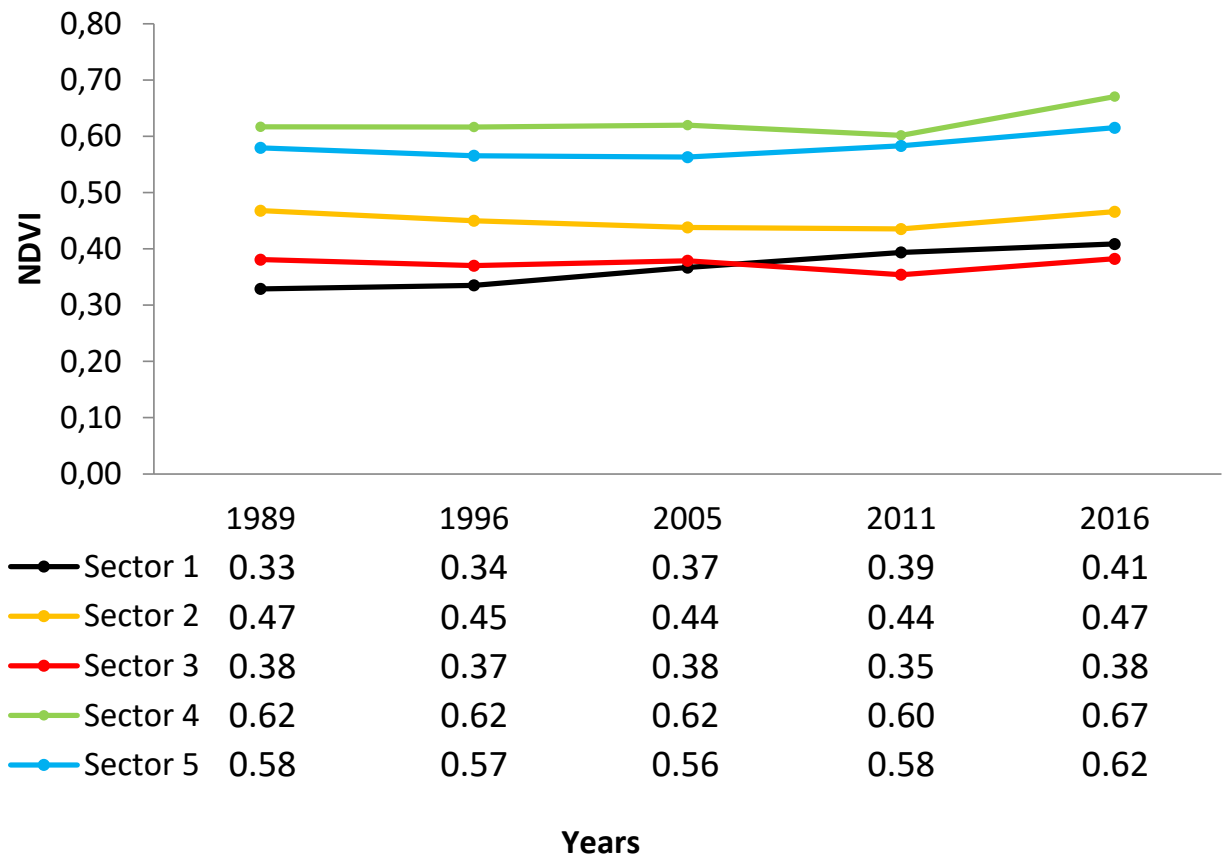


6,00

5,00

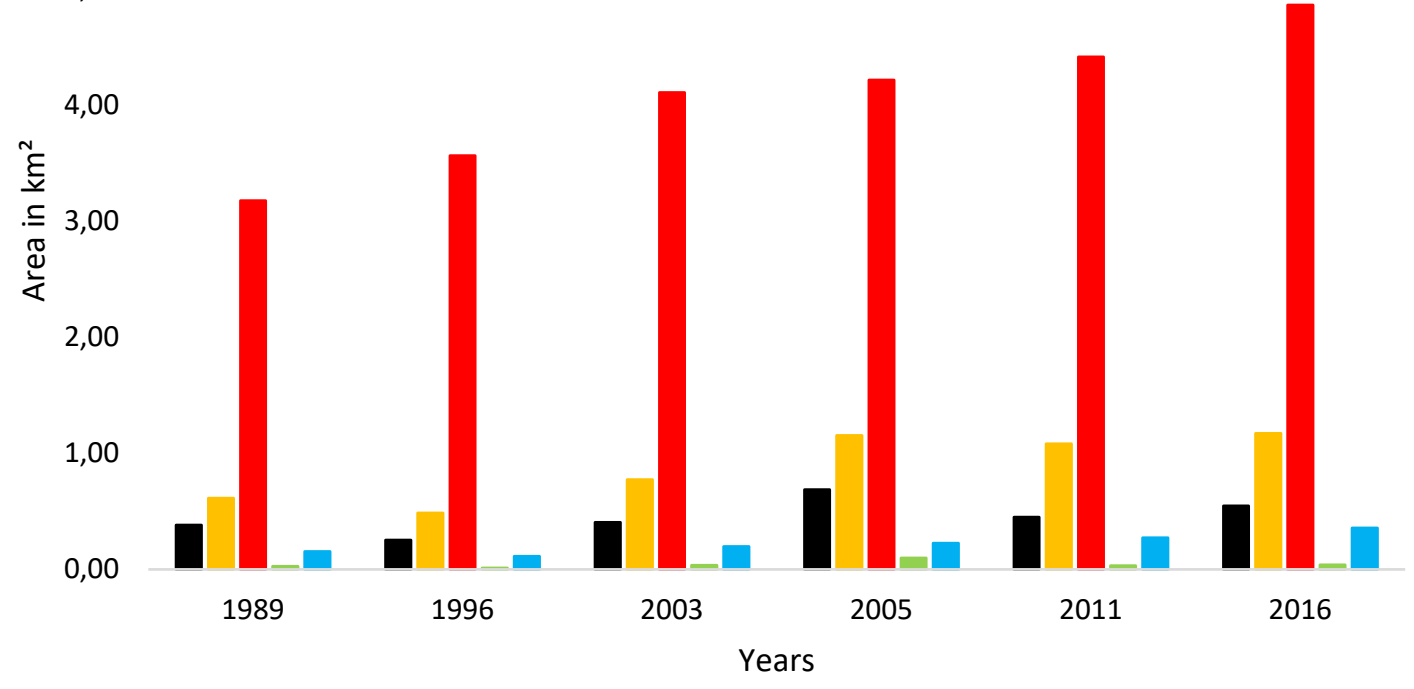

- Sector $1 \quad$ Sector $2 \quad$ Sector $3 \quad$ Sector $4 \quad$ Sector 5 
(a)

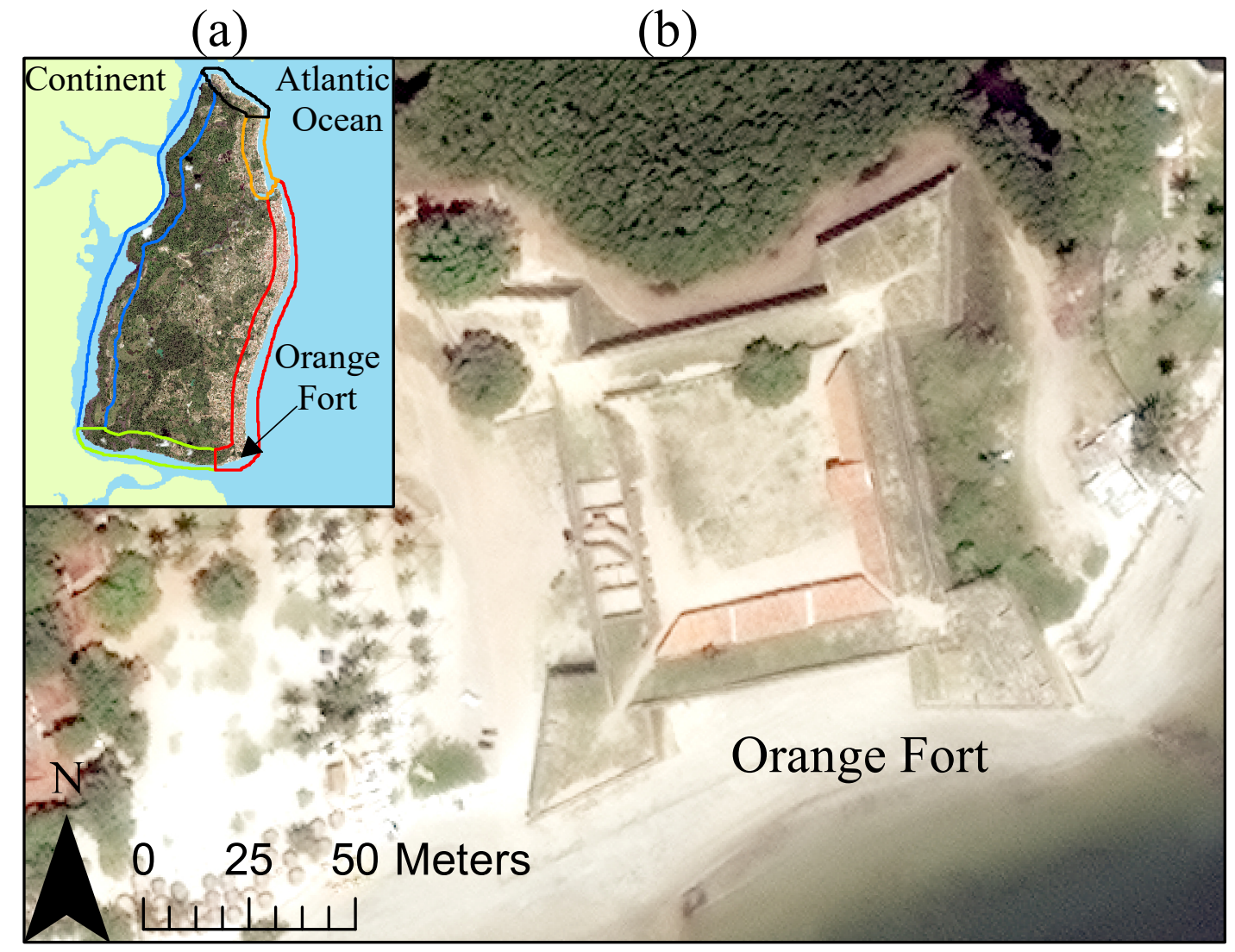

(c)

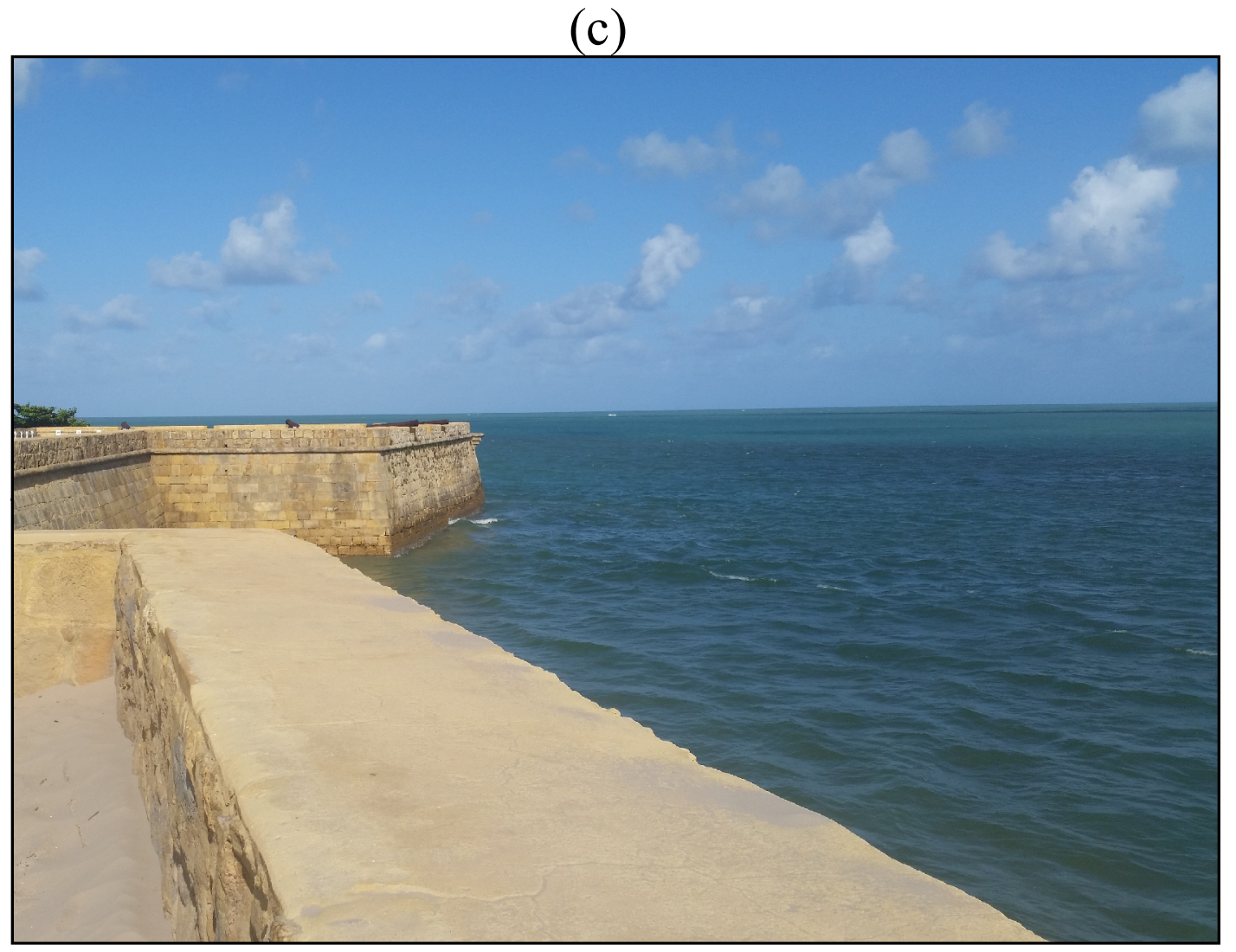




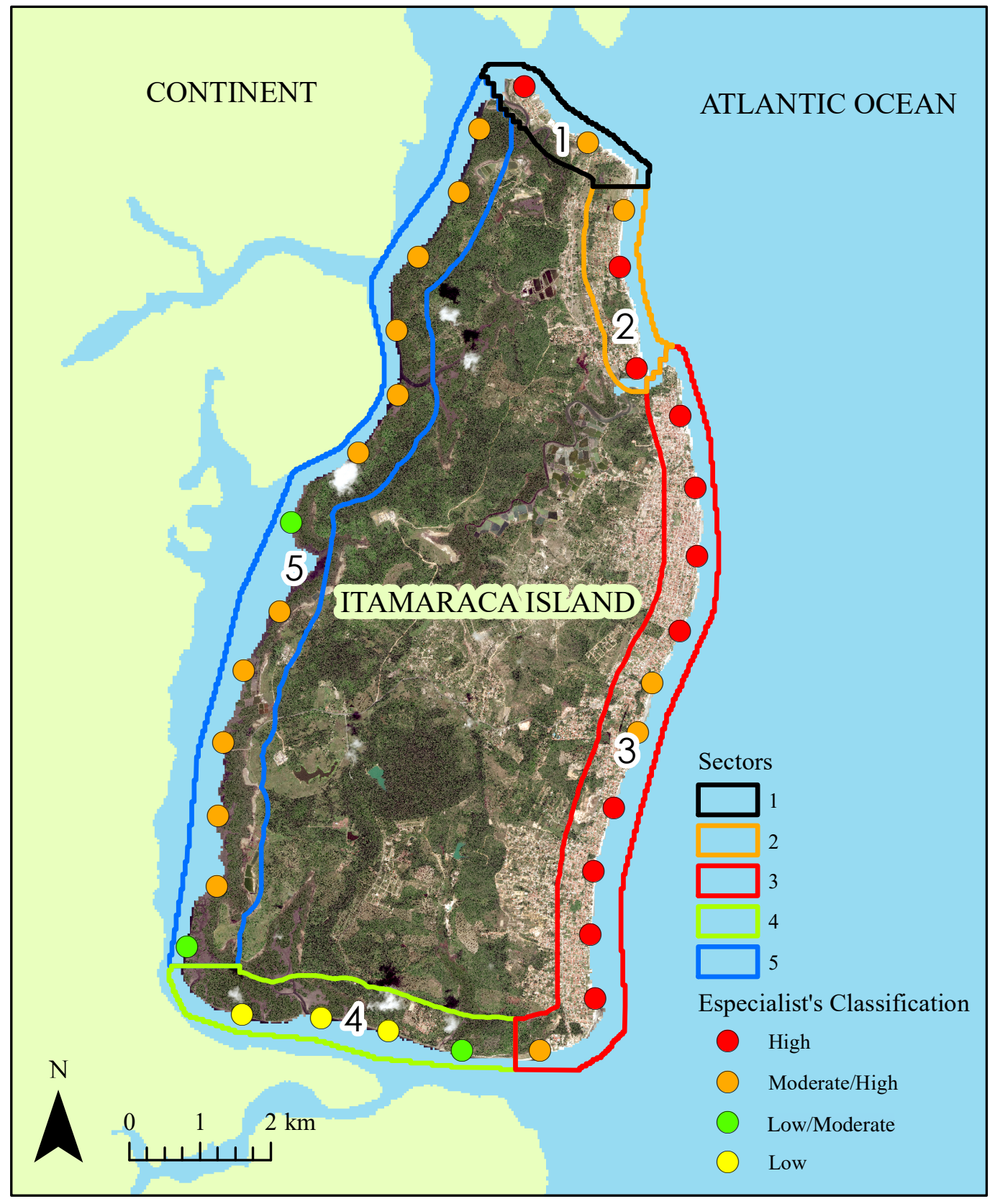




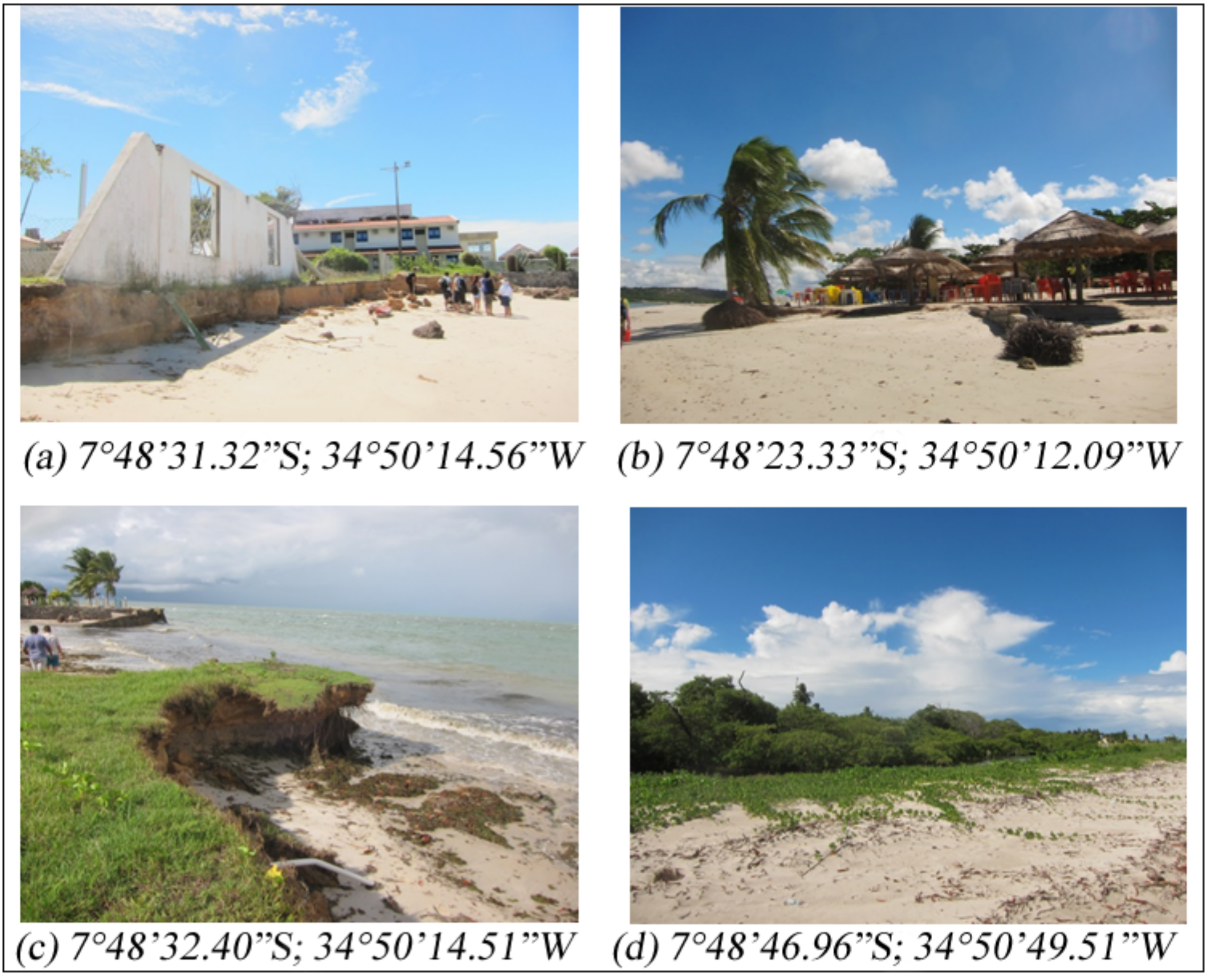

